\title{
The Impact of a Premium Based Tick Size on Equity Option Liquidity
}

\author{
Thanos Verousis ${ }^{a *}$ Owain ap Gwilym $^{b}$ and Nikolaos Voukelatos ${ }^{c}$ \\ ${ }^{a}$ School of Management, University of Bath, Bath, BA2 7AY, UK \\ ${ }^{b}$ Bangor Business School, Bangor University, Bangor, LL57 2DG, UK \\ ${ }^{c}$ Kent Business School, University of Kent, Kent, CT2 7PE, UK
}

\begin{abstract}
On June 2, 2009, NYSE LIFFE Amsterdam reduced the tick size for options trading at prices below $€ 0.20$ from $€ 0.05$ to $€ 0.01$ and on April 1, 2010, the exchange increased the price threshold to $€ 0.50$. We study the effect of that tick size reduction on the liquidity of individual equity options. In this respect, this study is uniquely positioned in the options context where moneyness is a clear additional factor in the implementation of the tick size changes. We show that, in general, quoted and traded option liquidity increased but at a rate decreasing with option moneyness. Real costs fell more for the lower priced contracts. Importantly, we show that the ability of the market to absorb larger trades has potentially diminished after the change in the tick size. We document a substantial increase in quote revisions which implies an increase in price competition and, as a result, an improvement in market quality. Finally, the decrease in the tick size led to an increase in hedging activity using deep-out-of-the-money puts.
\end{abstract}

Keywords: Liquidity, Tick Size, PBTS, Equity options, Amsterdam LIFFE JEL Classifications: G12, G20

\footnotetext{
${ }^{*}$ Corresponding author: +44 (0) 1225 386314, t.verousis@bath.ac.uk. We would like to thank participants at the Financial Management Association Europe 2014 conference, the French Finance Association 2014 conference, the High Frequency Data and Derivatives Markets conference, the $7^{\text {th }}$ Financial Risks International Forum, and seminar participants at the University of Bath and the Adam Smith Business School (University of Glasgow) for valuable comments and suggestions.
} 


\section{Introduction}

"The Participants are filing the proposed Plan in order to implement a pilot program for a one-year Pilot Period that, among other things, would widen the quoting and trading increments for certain small capitalization stocks (Tick Size Pilot Program)." (SEC, 2014-176)

"People are finally recognizing that the one-size-fits-all stocks is a disaster" (D. Weild, former VC of NASDAQ, in Massoudi and Mackenzie, 2013)

Since decimalization at US exchanges in 2001, regulators have engaged in a battle with the exchanges and market makers over whether small tick sizes enhance market quality. The debate surrounds the trade-off between reducing transaction costs for investors and incentivising market makers to support illiquid stocks. This paper contributes new evidence to this debate from a "natural experiment" for option contracts trading at NYSE LIFFE.

On June 2, 2009, NYSE LIFFE introduced the Premium Based Tick Size rule (henceforth PBTS) on all single stock options trading at NYSE LIFFE Amsterdam. According to the new rule, equity options trading at a premium of $€ 0.20$ or lower could be quoted at a tick size of $€ 0.01$, whereas options trading at prices higher than the threshold continued to be quoted at a minimum tick of $€ 0.05$. On April 1, 2010, NYSE LIFFE increased the price threshold from $€ 0.20$ to $€ 0.50$. This paper presents evidence on the effect of the implementation of the PBTS on the quote and trade liquidity of individual equity options. Our study is uniquely positioned in the options context where moneyness is a clear additional factor in the implementation of the tick size changes.

Theoretically, Harris (1994) suggests that a decrease in tick size is expected to lead to a narrowing of bid-ask spreads if the current tick size is greater than the size that would be quoted if no minimum tick was enforced. Most importantly, spreads are expected to narrow more for the lower priced assets for which the minimum tick size is a more binding constraint. Also, to the extent that there is a negative association between trading volume and spreads, the reduction in tick size would increase trading volume. Meanwhile, market depth is expected to decrease, because traders desiring to trade large sizes may be deterred since the small tick size increases the probability that other smaller traders may step ahead of them in the order book. On this latter point, Portniaguina et al. (2006) show that in hybrid markets like the NYSE, a reduction in tick size reduces the value of a limit order. This may lead to the order book becoming very thin and quoted spreads becoming very wide. The authors show that a decrease in the minimum tick size increases the cost of submitting large orders and subsequently leads to 
order splitting (stealth trading). However, the effect of this change on specialist participation rates is not expected to be uniform. For stocks with a smaller initial average trade size, order splitting should not be as prevalent as for firms with large initial trade sizes. Portniaguina et al. (2006) show that market maker profits will be positive for the former stocks and less positive, or possibly negative, for the latter.

Empirically, in equity and futures markets, several studies have shown that a reduction in tick size delivers two main outcomes. Firstly, spreads generally narrow (see Harris, 1991, 1994; Seppi, 1997; Bollen and Whaley, 1998; Goldstein and Kavajecz, 2000; Jones and Lipson, 2001; Bessembinder, 2003; Smith et al., 2006). Secondly, market depth deteriorates as a smaller tick size makes front running more profitable for smaller investors and increases order transparency for large traders (see Harris, 1996; Angel, 1997; Goldstein and Kavajecz, 2000; Jones and Lipson, 2001). The latter implies an overall increase in liquidity for small trades and an overall decrease for institutional trades. Also, Bourghellea and Declerck (2004) show that a tick size change is not necessarily associated with a change in liquidity supply but primarily affects order submission strategies. This is due to the fact that a decrease in the tick size fails to attract liquidity providers on the limit order book and, if the spread remains unaffected, depth generally still reduces.

The debate is far from having been resolved in favour of smaller tick sizes. In 2001, NASDAQ and NYSE replaced the fractional price system with decimal prices, cutting the tick size to one cent for both markets. However, in June 2013, the U.S. Securities and Exchange Commission was reported to have drafted a pilot program that would increase the tick size for 100 of the smaller or less liquid US stocks (see Mamudi and Michaels, 2013). On August 26, 2014, the U.S. Securities and Exchange Commission filed a plan to implement the 12-month pilot program whose outcomes "could have meaningful implications for market quality" (SEC, 2014-176). This was in response to criticism from the financial industry that "decimalization - a euphemism for the collapse in trading spreads, tick sizes and commissions - decimated the U.S. IPO market" (Weild et al., 2012, p. 2). In their view, it is crucial to provide economic incentives to market makers in order that they continue supporting small stocks and provide analyst coverage. In this respect, our study is extremely timely. Also, for NYSE LIFFE, market makers are an integral part of the trading process as, under their contractual obligations with the exchange, they are obliged to offer competitive two-way quotes across the whole spectrum of contracts that are trading at the exchange. Thus, the implementation of the PBTS may lead to lower profits for market makers which may serve as a disincentive to offer competitive quotes. On the other hand, Harris (1994) suggests that since market maker profits are a function of volume and spreads, their profits 
would increase overall if volume increases by more than the decrease in spreads. However, Al-Yahyaee (2013) shows that a decrease in tick size does not always lead to increases in trading volume.

Our findings suggest that while spread liquidity generally increased more for deep-out-of-the-money (DOTM) options, depth liquidity deteriorated more for contracts that are further in-the-money (ITM). This implies that, following the tick size changes, quoted liquidity generally increased for the DOTM and the outof-the-money (OTM) contracts, but at a decreasing rate for greater moneyness. Similarly, effective spreads decreased more than quoted spreads for contracts with low moneyness but the significance disappears as moneyness increases. For calls priced under $€ 0.20$, this drop in effective spreads is due to an overall decrease in real costs net of the price impact of trades. For contracts priced between $€ 0.20$ and $€ 0.50$, the decrease in spreads is due to a decrease in price impact rather than a decrease in real costs.

Importantly, we show that the ability of the market to absorb larger trades has diminished after the tick size change. However, as $60 \%$ of trades are retail (Noiville and Seblain, 2011), we expect that this decrease in liquidity has no effect for the majority of traders. Consistent with previous findings, trading activity generally increased after the tick size changes. We document an increase in the volatility for DOTM puts that potentially reflects a greater appetite for the crash insurance characteristics of DOTM puts. Finally, we document a substantial increase in quote revisions. This finding shows strong support for the hypothesis that the decrease in tick size has resulted in improved price competition for the average investor.

Our findings have important implications for optimal contract design in equity options markets. The goal of attracting liquidity has been achieved with two immediate implications: economic rents have been transferred from market makers to individual investors and the increase in liquidity has been realized at the expense of a thinner market for larger investors. The price/time priority rule may not operate effectively in circumstances when a large trade enters the market and, at such times, market makers should be allowed to increase their economic rents for facilitating abnormal trade sizes in ways similar to an upstairs market. A second possible scenario would be for the exchange to introduce a pro-rata algorithm that would circumvent the problem with the price priority rule when the tick size is too small.

The rest of the paper is organized as follows. Section 2 discusses the market structure. Section 3 discusses the positioning of the paper and outlines the testable hypotheses. Section 4 describes the data and research design issues, Section 5 presents the empirical results and Section 6 concludes. 


\section{$2 \quad$ NYSE LIFFE Amsterdam Market Structure}

NYSE LIFFE is the derivatives branch of NYSE for the European derivatives market, overseeing a total of five European markets (Amsterdam, Brussels, Lisbon, London and Paris). Liquidity is supported by the "Euronext Liquidity Provider System" (ELPS), where market makers are acting as liquidity providers with the obligation to submit continuous asks and bids in near-the-money contracts and receive trading rebates as a return. ${ }^{1}$

NYSE LIFFE implemented the new tick size for all options trading below $€ 0.20$, effective from June 2, 2009. The exchange stated that the "PBTS is designed to have the tick size match the level of the premium: a small tick size for lower prices and a large tick size for higher prices". Further, the exchange added that since the introduction of the new tick size, spreads have almost halved for the affected contracts (see PBTS, 2013).

The implementation of the PBTS rule on NYSE LIFFE Amsterdam is unique from several perspectives. First, trading at NYSE LIFFE is facilitated by ELPS. For Amsterdam, the exchange recognizes three types of liquidity providers, the Primary Market Makers (PMMs), the Competitive Market Makers (CMMs) and the Extra Competitive Market Makers (CMXs). Market makers' spread and size obligations are a function of the price and volatility of the underlying asset (updated semi-annually) and refer to maximum spread and minimum size. Spread and size obligations are therefore not uniform across all assets. All market makers are required to trade a minimum number of contracts of high liquidity assets. ${ }^{2}$ Trading fee reductions are not uniform and are based on a monthly evaluation of the market maker's performance. Second, an important feature of the ELPS in Amsterdam is that PMMs are obliged to offer two-way competitive quotes for the entire series of contracts for which they are contractually obligated to offer liquidity. PMMs are obliged to offer continuous quotes for at least $85 \%$ of the relevant number of series and during at least $85 \%$ of the specific time period. However, CMMs and CMXs are obliged to offer liquidity for the near-the-money contracts only. The above points imply that the implementation of the PBTS affects PMMs' quote obligations more than those of CMMs or CMXs, because the PBTS is more relevant for OTM options that are priced at lower levels than other contracts. Third, NYSE LIFFE Amsterdam is heavily populated by retail investors (see Noiville and Seblain, 2011) and concerns have been raised regarding the potential impact of PBTS on boosting the trading activity for OTM options, arguing that trading OTM contracts will remain too costly as brokerage retail fees are high, taking away any savings from trading at a smaller fee (Fooling retail

\footnotetext{
1 "How the Euronext.liffe markets work". Available on the NYSE LIFFE website.

${ }^{2}$ Asset liquidity and hence the number of market makers for each asset is assessed and defined by the exchange.
} 
investors with new tick size, 2009).

\section{Hypotheses}

The implementation of the PBTS is expected to have an effect on three features of trading in equity options: liquidity, trading activity and volatility. In this section, we develop appropriate hypotheses with respect to these anticipated effects.

While the empirical evidence on the effect of tick size reductions on asset liquidity is overwhelmingly positive for the spread aspect of liquidity, deteriorations in depth may lead to an overall increase in transaction costs for larger trades. Many studies report narrower spreads following a tick size reduction (see Harris, 1991 and 1994; Seppi, 1997; Bollen and Whaley, 1998; Bessembinder, 2003; Smith et al., 2006). However, Goldstein and Kavajecz (2000) and Jones and Lipson (2001) also report a decrease in depth for NYSE stocks after decimalisation. Moreover, for the UK Long Gilt futures market, ap Gwilym et al. (2005) show that, while depth decreased following a move to decimal pricing, the spread, measured in ticks, increased but its monetary value decreased. Regarding a hybrid measure of liquidity, Bessembinder (2003) reports that effective spreads generally declined for NYSE and NASDAQ stocks after decimalisation and that small capitalisation stocks benefited most from the reduction in tick size. None of the previous tick size studies has employed the quote slope as a hybrid measure of quote liquidity. We anticipate a reduction in quote slope if overall liquidity has increased. From the above points, we define the following hypotheses:

Contracts that trade under a smaller tick size will:

Hypothesis 1: Exhibit a decrease in quoted bid-ask spreads.

Hypothesis 2: Exhibit a decrease in depth.

Hypothesis 3: Exhibit an increase in trade and quote liquidity if the benefit from a reduction in the cost side of liquidity is greater than the cost of a decrease in liquidity supply.

Effective spreads can be further decomposed to two components: the price impact, which measures the losses of investors to informed traders, and the realized spread which measures the post-trade price reversal or equally the cost of providing liquidity net of losses to informed traders (see Bessembinder and Kaufman, 1997). If the smaller tick reduces spreads, both the price impact and the realized spread measures will fall as a consequence. In practice, this implies that there should be smaller price jumps in either direction with the smaller tick size. Most important, however, is the relative change of realized spreads to price impact. Realized spreads measure market making profits, hence a greater reduction in realized spreads as compared to price impact would imply that the hypothesized decrease in traded liquidity is more a function of a drop in real costs. We derive 
the following hypothesis:

Hypothesis 4: Price impact and realized spreads will be smaller for contracts that trade under the new tick size.

Harris (1994) shows that trading volume will increase following a decrease in tick size. Also, transaction frequency may increase because it is cheaper to trade smaller sizes and reduce the cost of being a counterparty to informed traders. Bacidore (1997) reports that trading volume did not significantly increase at the Toronto Stock Exchange following a reduction of tick size, and the same finding is reported for AMEX by Ahn et al. (1996). On the other hand, following an increase of the tick size for the S\&P500 futures contract trading at CME, Bollen et al. (2003) show an overall widening in spreads and a significant reduction in trading volume. Chakravarty et al. (2003) show that while trading volume and the number of trades increased for small NYSE stocks following decimalisation, there was a significant decrease in trading activity for large size trades. Harris (1994) also predicts that a reduction in tick size will have more visible effects on the trade liquidity of the more heavily traded stocks, because it is more likely that the previous larger tick size acted as a binding constraint for a narrowing of spreads on these stocks. We subsequently derive the following hypotheses:

Hypothesis 5: Contracts that trade under a smaller tick size will exhibit an overall increase in trading activity.

Hypothesis 6: Trade liquidity will increase more for assets that are more heavily traded.

An important aspect of the implementation of the PBTS is the expectation of an asymmetric effect on option contracts based on moneyness. In particular, PBTS is aligned to the option price and as a result the effect should be stronger for the OTM options, since these are the lowest priced options. PBTS is also expected to have a stronger positive effect for OTM contracts that are more likely to expire in-the-money. The probability of exercise is negatively related to moneyness, with deeper OTM options being less likely to be exercised at maturity, i.e. to expire ITM, ceteris paribus. In addition, the probability of exercise at maturity for OTM options with the same moneyness is positively related to the underlying asset's volatility. For instance, the price of a more volatile underlying asset is more likely to exceed at maturity the high strike price of a currently OTM call. A similar argument applies in the case of OTM puts, where the prices of more volatile underlying assets are more likely at maturity to fall below the low strike prices of currently OTM puts.

Overall, we hypothesize that as OTM options written on more volatile underlying assets have a higher probability of being ITM at expiration, the impact of tick size changes will be greater. A large tick size would constitute a greater constraint on trading these contracts with higher underlying volatility, and we an- 
ticipate a greater impact on their liquidity following a reduction of the tick size. In relation to the above, previous research suggests that if decreases in tick size are associated with lower liquidity then volatility should also increase (Harris, 1994; Bessembinder, 2003).

Hypothesis 7: Liquidity will increase by less as moneyness increases.

Hypothesis 8: The reduction in spreads for OTM options written on more volatile underlying assets after the implementation of the PBTS will be greater compared to that for equally OTM contracts written on less volatile assets.

Hypothesis 9: Option spreads that are affected by the PBTS will exhibit lower volatility reflecting an overall increase in liquidity.

Finally, while it is not possible to measure execution speed directly, we assume that the latter is related to the percentage of quote revisions per time interval. Specifically, a smaller tick size reduces the cost of stepping ahead of other traders in the order book, and we hypothesize that quote revisions may significantly increase for those contracts affected by the implementation of the PBTS. Furthermore, an increase in quote revisions implies more aggressive price competition among market participants, who update their quotes more often, to the benefit of market quality. Overall, we argue that an increase in quote revisions after the rules change will be beneficial to the average investor due to a higher probability of improving on quoted prices.

Hypothesis 10: The number of quote revisions will increase for the contracts that are affected by the PBTS.

\section{Research Design}

The intraday dataset contains information on maturity date, strike price, volume and price for all individual equity options (henceforth tickers), time-stamped to the nearest second, separately for asks, bids and trades. ${ }^{3}$ Each ticker is trading under different contracts, which vary by the strike price, maturity date and contract type, i.e. call or put (henceforth sub-tickers). We select options that expire within a maximum of 365 days, but not within seven days, in order to avoid any very short term expiration effects. Moneyness is defined as $S / K$, where $K$ refers to the option strike price and $S$ to the underlying unadjusted opening price. ${ }^{4}$ We categorize sub-tickers according to their moneyness and maturity. For calls, we

\footnotetext{
${ }^{3}$ The number of tickers reflects the total number of firm-options trading and it includes delisted options.

${ }^{4}$ End-of-day prices for the underlying stocks are obtained from DataStream. All options in the sample are American style. We drop options with weekly and daily expiry cycles. In total, 90 percent of contracts are maintained in the final sample.
} 
define DOTM contracts as those with moneyness smaller than 0.9, OTM contracts as those with moneyness between 0.9 and 1 , and in-the-money (ITM) contracts as those with moneyness between 1 and 1.1. We drop deep-in-the-money contracts (calls with moneyness $>1.1$ ), as very few observations fall in this category. The opposite classification is used for puts.

We delete outliers based on the following criteria. All zero price and out-ofhours observations are deleted, as are quotes with negative or zero bid-ask spreads. ${ }^{5}$ Also, as in Wei and Zheng (2010), we control for outliers by dropping quotes with extreme bid-ask spreads (exceeding $150 \%$ and $200 \%$ for ITM and OTM options, respectively).

We focus on a 300-day window around the two stages of the PBTS. The sample is split into four sub-periods. Sub-periods 1 and 2 refer to the days before (January 3, 2009 to June 1, 2009) and after (June 2, 2009 to October 30, 2009) the initial implementation of the PBTS at a threshold price of $€ 0.20$ (henceforth Stage 1). Sub-periods 3 and 4 refer to the days before (November 2, 2009 to March 31, 2010) and after (April 1, 2010 to August 29, 2010) the increase of the price threshold to $€ 0.50$ (henceforth Stage 2).

Quoted spreads, depths and option returns are estimated using 5-minute subticker mid-quotes. On each trading day, we retain bid and ask quotes at 5-minute intervals. We control for stale pricing by dropping bids and asks that are recorded more than two minutes prior to each 5-minute interval. We drop the opening and closing intervals, leaving us with $n=101$ intervals in total.

The most commonly used spread measure is the quoted bid-ask spread, defined as the difference between the most recent ask and bid prices (e.g. Petrella, 2006; Wei and Zheng, 2010). We control for price level differences by calculating the percentage bid-ask spread $(P B A S)$, defined as the ratio of quoted spread over the quote midpoint:

$$
P B A S_{i}=100 \times \frac{A s k_{i}-B i d_{i}}{M_{i}}
$$

where $A s k_{i}$ and $B i d_{i}$ are the ask and bid prices sampled at the 5-minute interval $i$, respectively, and $M_{i}$ is the corresponding midquote. Quoted depth represents a reciprocal measure of liquidity (see Harris, 1990). We measure quoted depth (Depth) in number of contracts as

$$
\text { Depth }_{i}=\frac{\text { Volume }_{\text {ask }, i}+\text { Volume }_{\text {bid }, i}}{2}
$$

\footnotetext{
${ }^{5}$ The exchange is open between 08:00 and 16:30 (GMT). We delete half-days. There are no zero-volume trades in the raw dataset, which is an important distinction from datasets where market orders may contain zero volume (pre-reporting).
} 
where Volume $_{a s k, i}$ and Volume $_{b i d, i}$ refer to the number of contracts quoted at the ask and bid prices, respectively, during the 5-minute interval $i$. The Log Quote Slope combines the price information from spreads and the quantity information from depths, and is defined as

$$
\operatorname{LogQuoteSlope}_{i}=\frac{\log \left(\text { Ask }_{i} / \text { Bid }_{i}\right)}{\log \left(\text { Volume }_{a s k, i}\right)+\log \left(\text { Volume }_{b i d, i}\right)}
$$

The Log Quote Slope measures the slope of a line connecting the bid and ask price/quantity pairs (Hasbrouck and Seppi, 2001). Hence, liquidity will improve if depth increases or if spread narrows. The Effective Half Spread is used as a second measure of hybrid liquidity because, even though it does not contain a direct measure of quoted depth, it provides an ex-post estimate of the effect of a large trade on the best bid and ask. If, for example, a large trade has consumed more than one level of the limit order book, the effective spread will be wider than the quoted spread. The realized spread is a measure of transaction costs net of price impact. The latter is a measure of adverse selection costs. ${ }^{6}$

We calculate effective spreads as follows (see Venkataraman, 2001):

$$
\text { EffSpread }_{i}=200 \times D \times \frac{\text { Price }_{i}-\text { Midquote }_{i}}{\text { Midquote }_{i}}
$$

where $D$ is a trade indicator dummy that takes the value of -1 if the trade is classified as a sell and +1 if it is classified as a buy. We use the quote method to classify trades. For the trades that are not classified, we use the trade method. ${ }^{7}$ Less than one percent of trades are not identified with either method and these are dropped from the sample. We calculate the price impact and the realized spread as follows:

$$
\begin{gathered}
\text { PriceImpact }_{i}=200 \times D \times \frac{\text { Midquote }_{i+1}-\text { Midquote }_{i}}{\text { Midquote }_{i}} \\
\text { RealSpread }_{i}=200 \times D \times \frac{\text { Price }_{i}-\text { Midquote }_{i+1}}{\text { Midquote }_{i}}
\end{gathered}
$$

\footnotetext{
${ }^{6}$ The estimated values from (5) and (6) will not always sum to that from (4), because effective spread is computed using the most recent bids and asks, while price impact is computed using the 5 -minute midquote.

${ }^{7}$ The quote method classifies a trade as a buy (sell) if it is at the prevailing ask (bid) price. The trade rule classifies a trade as a buy (sell) if it is above (below) the previous trade. If there is no price change but the previous trade was a buy (sell), then the trade is classified as a buy (sell).
} 
where Midquote $_{i+1}$ refers to the midquote recorded within a four-minute to eightminute time frame after each trade.

We compute realized volatility $\mathrm{Vol}$ from intraday returns (computed at the midquote). In order to alleviate potential problems when estimating volatility in less liquid markets and in the presence of jumps, we use the absolute (rather than the squared) value of intraday returns, after dropping returns that lie further than 3 standard deviations from their ticker-specific mean. We report the standard deviation of absolute intraday returns. The trading activity variables (number of transactions, trade volume and trade size) refer to daily averages.

Comparisons across sub-periods 1 and 2, and across 3 and 4 are based on contracts that are priced below $€ 0.20$ and $€ 0.50$, respectively. First, we assign all contracts to baskets according to their type (call/put) and moneyness (DOTM, OTM, ITM). All variables are calculated per asset and sub-period. We then perform a t-test and non-parametric Wilcoxon rank sum test on the differences in the cross-sectional variation of the ticker-specific variables for the differences between sub-periods 1 and 2, and separately for sub-periods 3 and 4 . The reported estimates are based on equally-weighted averages across tickers for each sub-period.

We estimate the effect of tick size changes on liquidity by employing the following Difference-in-Difference (DiD) model that will allow us to control for the contemporaneous effects with a set of contracts that are trading at the same time when the changes took place. ${ }^{8}$

$$
\text { Liq }_{i, t}=\alpha+\beta \times \text { Treat }_{i, t}+\gamma \times \text { Post }_{t}+\delta \times \text { Treat }_{i, t} \times \text { Post }_{t}+\epsilon \times V_{i, t}+z_{i, t}
$$

Liq is the liquidity variable of interest (quoted spread, effective spread, depth, price impact, realized spread). Treat is a dummy variable that takes the value of 1 for options that are affected by the implementation of the PBTS, i.e. options priced equal to or below $€ 0.20$ in the first set of regressions, and options priced between $€ 0.20$ and $€ 0.50$ in the second set of regressions. Post is a dummy variable that takes the value of 1 for dates after the implementation of the PBTS. For the first (second) set of regressions, Post takes the value of 1 during sub-period 2 (sub-period 4). The base periods refer to sub-periods 1 and 3, respectively. Finally, $V$ is a vector of control variables for the options and the underlying market, which includes the reciprocal of price 1/Price $(\mathrm{Pr})$, return volatility $(\mathrm{Vol})$ and the natural logarithm of trading volume $(\operatorname{Tr} V)$ for the options market. Volume is excluded when depth is the dependent variable. We anticipate that liquidity will be positively related to the reciprocal of price and to volatility and negatively related to volume (see Chung et al., 2004, Harris, 1994). For the underlying market,

\footnotetext{
${ }^{8}$ In a related context, Marsh and Payne (2012) use a DiD approach to investigate the effect of short sale restrictions on market quality indicators.
} 
we include the natural logarithm of the market capitalization of the underlying asset $(M V)$, underlying volatility $(\mathrm{Vol})$ and the closing percentage bid-ask spread (PBAS). We use the range estimator as a measure of the underlying market volatility (see Petrella, 2006). We expect higher liquidity for the larger assets. Also, we expect liquidity to deteriorate with increasing levels of PBAS and with decreasing levels of underlying volatility (see Wei and Zheng, 2010).

The DiD allows us to extract the following information. First, $\alpha$ reflects the liquidity of options that are not affected by the PBTS rule during the time before the implementation of the PBTS rule. Second, $\beta$ reflects the liquidity of options that are affected by the PBTS rule before the implementation of the PBTS rule. Third, $\gamma$ quantifies the change in the liquidity of options that are not affected by the PBTS rule after the implementation of the PBTS rule. Finally, $\delta$ picks up the change in the liquidity of options priced below the price threshold after the implementation of the PBTS rule.

In order to estimate Equation (7), the control group includes all options that are priced under $€ 1.00$ but greater than $€ 0.50$, in order to maintain the price level within a finite range. We estimate Equation (7) separately for calls and puts and also for each moneyness level. All regressions are reported with double-clustered robust standard errors that allow for dependence across time and also across stocks (see Marsh and Payne, 2012).

\section{Empirical Results}

Table 1 presents the effect of the implementation of the PBTS on the liquidity measures, separately for calls and puts and also across moneyness levels. In line with Hypothesis 1, quoted spreads for contracts priced below the PBTS threshold declined significantly. For instance, in the $1^{\text {st }}$ stage of the PBTS, the average quoted spread for DOTM calls reduced by $34 \%$, while spreads for OTM and ITM calls fell by $49 \%$ and $55 \%$, respectively. Similar spread declines are observed for puts, and all spread differences are statistically significant. Spread reductions in the $2^{\text {nd }}$ stage of the PBTS are also consistently significant, albeit somewhat lower. However, the increase in quoted spread liquidity is followed by a larger decrease in quoted depth liquidity. Consistent with Hypothesis 2, quoted depth has dropped substantially for calls and puts across all moneyness levels, with these declines being highly significant across all moneyness levels for the larger price threshold. Another important finding is that, in contrast to the large variations before the implementation of the PBTS, the number of quoted contracts post-PBTS remains relatively constant across moneyness levels.

[Insert Table 1 around here] 
Hypothesis 3 is supported by the substantial increases that are observed in quote and trade liquidity. For instance, the Log Quote Slope decreased by $21.42 \%$ for DOTM calls and the effective spread decreased by $48.36 \%$ after the $1^{\text {st }}$ stage of the PBTS. This finding is consistent across both calls and puts of all moneyness levels, for both stages of the PBTS. Overall, these results suggest that, along with increased quoted liquidity after the implementation of the PBTS, effective spreads demonstrated an even greater proportional decrease.

Figure 1 presents the evolution of quoted depth and spread for calls during 100-day windows surrounding the two implementation stages of the PBTS rule. During the $1^{\text {st }}$ stage of the PBTS, the decline of quoted spreads after the new rule was gradual, with a new stable level reached after 10 days, while quoted depths decreased substantially on the first day of the new tick size. During the $2^{\text {nd }}$ stage of the PBTS, a sharp decrease in quoted spreads is observed on the first day of the change, implying that the larger tick size is more binding for options with higher prices.

[Insert Figure 1 around here]

As can be seen from Figure 2, which reports the outcomes of the same exercise for quote and trade liquidity, the increase in liquidity is constrained by the decrease in quoted depth. During the $1^{\text {st }}$ stage of the PBTS (and for DOTM options during the $2^{\text {nd }}$ stage), trade liquidity declines significantly while quote liquidity remains relatively constant, suggesting that the drop in depth becomes larger as moneyness increases. We investigate this further below.

[Insert Figure 2 around here]

At this point, an interesting question arises about the extent to which larger trades are affected by the reduction in quoted depth. Figure 3 attempts to answer this question, examining DOTM and OTM contracts, for which the order book is thinner (results are similar for ITM contracts). Here, we plot the cross-sectional quoted depth from Figure 1 against the average trade size, in the days surrounding the two tick size changes. We also construct confidence bands of 1 and 2 standard deviations from the average trade size. We expect that $68 \%(95 \%)$ of trades will lie within 1 (2) standard deviation(s) from the mean on any given day.

[Insert Figure 3 around here]

Before the rule changes, the average trade size was substantially lower than the 
average quoted depth, suggesting that plentiful liquidity existed at the best bid and ask to accommodate larger trades. Post-PBTS, the quoted depth decreased significantly while the average trade size remained unchanged. When the trade size's confidence bands lie above the quoted depth, larger trades will not be executed at the best bid/ask and will need to be filled further down in the order book (even though the market can still accommodate the average trade). The overall situation for investors who wish to trade large quantities is that they initially benefit from the narrower bid-ask spread but, as their order is now less likely to be fully executed at the top of the order book, they will have to then trade at inferior prices further down the order book. The exact economic effect of this trade-off will not be uniform across all trades and it can only be determined by examining the full order book (which is not available to us). However, as the trade size increases, an order must be processed at progressively inferior prices down the order book while the benefit of a narrower initial spread remains fixed. Therefore, the larger the trade size, the more likely that this trade-off has a negative net effect.

Table 2 investigates the components of the effective half spread. After the implementation of the PBTS, effective spreads fell as a result of both the price impact costs and the realized spreads falling, consistent with Hypothesis 4. However, the relative impact of these two components of effective spreads was not uniform. In the $1^{\text {st }}$ stage of the PBTS, the reduction in trade costs reported in Table 1 is driven primarily by a decrease in realized spreads, which is consistent with market makers losing revenues as they are obliged to provide liquidity in DOTM options. In contrast, in the $2^{\text {nd }}$ stage of the PBTS, the reduction in realized spreads is relatively smaller than that in price impact, suggesting that the reduction in trade costs is driven mainly by the latter element.

\section{[Insert Table 2 around here]}

The results from Table 3 are consistent with Hypothesis 5. Trading activity significantly increased after the rule changes, with OTM (DOTM) contracts experiencing their biggest volume difference during the $1^{\text {st }}\left(2^{\text {nd }}\right)$ stage of the PBTS. DOTM puts were more heavily affected than DOTM calls, which could be indicative of investors' appetite for the crash-insurance characteristics of DOTM puts, especially during the declining spot market of the sample period. Furthermore, the transaction frequency increased significantly, with OTM contracts experiencing the largest increase $\left(172 \%\right.$ for calls and $217 \%$ for puts during the $1^{\text {st }}$ stage). It is worth noting that the trading volume of DOTM puts increased by more than their transaction frequency, reflecting an increase in the average trade size.

[Insert Table 3 around here] 
Table 4 presents evidence in support of Hypothesis 6 . We classify tickers in subperiods 1 and 3 according to their transaction frequency, assign them to quartiles in sub-periods 2 and 4 based on the previous transaction frequency, and estimate effective half-spreads. As hypothesized, the narrowing of spreads was more pronounced for tickers with the highest number of trades in DOTM and OTM calls and puts. At the extreme, contracts in the low frequency category were associated with zero spread changes in the $2^{\text {nd }}$ stage. However, ITM contracts experienced the greatest narrowing in spreads in the medium frequency category.

[Insert Table 4 around here]

Table 1 reports that liquidity increases more as moneyness increases, in contrast to Hypothesis 7. However, as we will show later, this initial result is not supported when we control for other changes in the DiD regressions.

For each stage, we use the period before the PBTS implementation to sort tickers into 3 groups according to the underlying assets' volatilities, then we estimate the average Log Quote Slope before and after the tick size change. The results (reported in Table 5) support Hypothesis 8. In particular, for DOTM and OTM options, quote liquidity increases by more for contracts with higher underlying volatility, while the reverse is true for ITM options. The intuition supported by these results is that OTM (ITM) contracts with higher underlying volatility are more (less) attractive than their lower volatility counterparts, hence are more (less) likely to benefit from a reduced tick size.

[Insert Table 5 around here]

Table 3 provides some support for Hypothesis 9, because volatility during the $1^{\text {st }}$ stage of the PBTS is found to decrease by more as moneyness increases. However, decreases in volatility are fairly similar across moneyness groups during the $2^{\text {nd }}$ stage of the PBTS.

We evaluate the effect of the PBTS on execution speed by examining quote revisions. We use the entire time-series at the best bid/ask (rather than sampling every 5 minutes) and we define as a price improvement every new best bid (ask) that is higher (lower) than the previous one. ${ }^{9}$ We subsequently compute the percentage of quote improvements per sub-ticker per day, with the results presented in Table 6 and Figure 4. For options priced below $€ 0.20$, quote improvements increased by $274 \%$ (259\%) for DOTM calls (puts), with smaller changes reported

\footnotetext{
${ }^{9}$ The procedure is conducted in tick time and not in clock time as there are several new quotes per second.
} 
as moneyness increases (reaching $-3 \%$ for ITM puts). During the $2^{\text {nd }}$ stage of the PBTS, quote improvements experienced a similar increase for DOTM contracts, but they exceeded $100 \%$ for OTM and ITM options. This finding is an outcome of the price level effect, as traders have more opportunities to step ahead in higher priced contracts. Overall, the results provide support for Hypothesis 10, which states that quote revisions would increase after the tick size reduction, which is potentially damaging for larger traders. This change is likely to have had a significant effect on the order book, as it allows traders to take advantage of the price priority rule and potentially step ahead of larger trades. However, we are unable to provide further specific evidence of this.

[Insert Figure 4 around here]

[Insert Table 6 around here]

The final aspect of our analysis involves estimating the DiD regression in (7) in order to quantify the differences in liquidity for tickers affected by the PBTS, controlling for liquidity changes in tickers that are unaffected by the PBTS.

\section{[Insert Table 7 around here]}

Table 7 presents the results with dependent variables being quoted spread and depth. In order to conserve space, we report results for calls only (results for puts are similar and available upon request). Similarly to our previous findings, quoted spreads generally narrowed after the tick size reduction. However, after controlling for the price level, volatility and volume, spreads fell by more for lower moneyness contracts, supporting Hypothesis 7. As anticipated, liquidity is positively associated with price and volatility, but negatively associated with volume. Quoted spreads are smaller for larger firms and increase as the underlying asset's spread increases. The underlying asset volatility is inversely related to liquidity for the lower-priced options, but not significantly for the higher-priced contracts. Furthermore, quoted depth decreases by more as moneyness increases. Overall, our findings suggest that contracts that are further OTM have benefitted more from the tick size change, experiencing the largest narrowing in spread and the smallest decrease in depth.

[Insert Table 8 around here]

Table 8 presents the DiD results for quote and trade liquidity. As expected, effective half spreads are smaller and they have experienced a smaller change in 
liquidity compared to quoted spreads, across both PBTS stages. Also, spreads for the control group have remained constant across the two sub-periods, as evidenced by the insignificant coefficients for Post in the $2^{\text {nd }}$ stage. Spreads decrease by more as moneyness increases, providing further evidence in support of Hypothesis 7 . A final finding in support of the PBTS having an overall positive effect on quote and trade liquidity relates to the increase in quote liquidity post-PBTS, as identified by the significantly negative coefficient for the Treat $\times$ Post variable.

\section{Conclusions}

The debate over adopting a reduced tick size is on-going and has significant implications for market liquidity, particularly in terms of striking an appropriate balance between lower trading costs for investors and adequate incentives for market makers to support illiquid assets. This paper uses data from a "natural" experiment of two consecutive reductions in tick size occuring at the NYSE LIFFE equity option market in order to explore the impact of tick size changes on liquidity.

Our results suggest that, while quoted spread decreased more for deep OTM options, quoted depth deteriorated more for options that are further ITM, implying an increase in overall liquidity for OTM contracts but a decrease for ITM ones. Effective spreads decreased more than quoted spreads for contracts with low moneyness, but the significance disappears as moneyness increases. For the lower-priced contracts, the drop in effective spreads is due to a decrease in real costs net of the price impact of trades, but the decrease in real costs disappeared when the price threshold increased.

Importantly, we show that the ability of the market to absorb larger trades has diminished after the change in the tick size. However, this reduced capacity to absorb large trades may not impact the vast majority of traders in this market because it is heavily populated by retail investors who typically engage in smaller trades. We document a substantial increase in quote revisions which implies that the decrease in tick size has increased price competition among market participants. Finally, we document an increase in trading activity for deep OTM contracts, which is associated with a substantial increase in option volatility.

These findings have important implications for optimal contract design in equity option markets. The goal of attracting liquidity has been achieved with two immediate implications: economic rents have been transferred from market makers to individual investors and the increase in liquidity has been realized at the expense of a thinner market for larger investors. The price/time priority rule may not be effective when a particularly large trade enters the market, and in such instances, market makers could be allowed to increase their economic rents for facilitating abnormal trade sizes in a manner similar to an upstairs market. A sec- 
ond possible scenario would be for the exchange to introduce a pro-rata algorithm that will circumvent the problem with the price priority rule when the tick size is too small. 


\section{References}

[1] Ahn, H., Cao, C. and H. Choe. 1996. Tick size, spread, and volume. Journal of Financial Intermediation 5, 2-22

[2] Al-Yahyaee, K. H. 2013. The effect of a reduction in price discreteness on exday stock returns in a unique environment. Journal of International Financial Markets, Institutions and Money 23, 283-294

[3] Angel, J.J. 1997. Tick size, share prices and stock splits. Journal of Finance, 52 , pp. $615-681$

[4] ap Gwilym, O., McManus, I. and S. Thomas. 2005. Fractional versus decimal pricing: Evidence from the UK Long Gilt futures market. Journal of Futures Markets 25, 419-442

[5] Bacidore, J. 1997. The impact of decimalisation on market quality. Journal of Financial Intermediation 6, 92-120

[6] Bessembinder, H. 2003. Trade execution costs and market quality after decimalization. Journal of Financial and Quantitative Analysis 38, 747-777

[7] Bessembinder, H. and H. M. Kaufman. 1997. A comparison of trade execution costs for NYSE and NASDAQ listed stocks. Journal of Financial and Quantitative Analysis 32, 287-310

[8] Bollen, N. and R. Whaley. 1998. Are 'teenies better? Journal of Portfolio Management 25, 10-24

[9] Bollen, N., Smith, T. and R. Whaley. 2003. Optimal contract design: For whom?. Journal of Futures Markets 23, 719-750

[10] Bourghellea, D and F. Declerck. 2004. Why markets should not necessarily reduce the tick size. Journal of Banking \& Finance 28, 373-398

[11] Chakravarty, S., Panchapagesan, V. and R. Wood. 2003. Institutional trading patterns and price impact around decimalization. Working paper, Purdue University

[12] Chung, K., B. Van Ness and R. Van Ness. 2004. Trading costs and quote clustering on the NYSE and NASDAQ after decimalization. Journal of Financial Research 27, 309-328

[13] Fooling retail investors with new tick size. 2009. $<$ http://www.amsterdamtrader.com> 
[14] Goldstein, M. and K. Kavajecz. 2000. Eighths, sixteenths, and market depth: changes in tick size and liquidity provision on the NYSE. Journal of Financial Economics 56, 125-149

[15] Harris, L. 1990. Liquidity, trading rules and electronic trading systems. New York University Monograph Series in Finance and Economics, No. 1990-4

[16] Harris, L. 1991. Stock price clustering and discreteness. Review of Financial Studies 4, 389-415

[17] Harris, L. 1994. Minimum price variations, discrete bidask spreads and quotation sizes. Review of Financial Studies 7, 149-178

[18] Harris, L. 1996. Does a large minimum price variation encourage order exposure? Working paper, University of Southern California

[19] Hasbrouck, J. and D. Seppi. 2001. Common factors in prices, order flows, and liquidity. Journal of Financial Economics 59, 383-411

[20] Jones, C. and M. Lipson. 2001. Sixteenths: direct evidence on institutional execution costs. Journal of Financial Economics 59, 253-278

[21] Mamudi, S. and D. Michaels. 2013. Exchanges Said to Prepare Pilot Programs for Changing Tick Sizes. Bloomberg

[22] Massoudi, A. and M. Mackenzie. 2013. SEC to consider increasing 'tick size'. FT.com.

[23] Marsh I. and R. Payne. 2012. Banning short sales and market quality: The UK's experience. Journal of Banking \& Finance 36, 1975-1986

[24] Noiville, V. and B. Seblain. 2011. Individual investors on the cash market. TNS Sofres

[25] PBTS. 2013. In NYSE Euronext Global Derivatives. Retrieved from https://globalderivatives.nyx.com/stock-options/nyse-liffe/pbts

[26] Petrella, G. 2006. Option bid-ask spread and scalping risk: Evidence from a covered warrants market. Journal of Futures Markets 26(9), 843-867

[27] Portniaguina, E., Bernhardt, D. and E. Hughson. 2006. Hybrid markets, tick size and investor trading costs. Journal of Financial Markets 9, 433-447

[28] Securities and Exchange Commission. 2014. Plan to implement a tick size pilot program. Washington DC 
[29] Seppi, D.J. 1997. Liquidity provision with limit orders and a strategic specialist. Review of Financial Studies 10, 103-150

[30] Smith, B.F., Alasdair, D., Turnbull, S. and R. W. White. 2006. The impact of pennies on the market quality of the Toronto Stock Exchange. The Financial Review, 41, 273-288

[31] Venkataraman, K. 2001. Automated versus Floor Trading: An analysis of execution costs on the Paris and New York Exchanges. Journal of Finance 56, $1445-1885$

[32] Wei, J. and J. Zheng. 2010. Trading activity and bid-ask spreads of individual equity options. Journal of Banking \& Finance 34, 2897-2916

[33] Weild, D., Kim, E. and L. Newport. 2012. The trouble with small tick sizes. Grant Thornton Capital Markets Series 
Table 1: Measures of Quoted and Traded Liquidity

\begin{tabular}{|c|c|c|c|c|c|c|c|c|}
\hline & & & \multicolumn{3}{|c|}{ Calls } & \multicolumn{3}{|c|}{ Puts } \\
\hline & & & DOTM & OTM & ITM & DOTM & OTM & ITM \\
\hline \multirow[t]{6}{*}{ Quoted Spread } & $1^{\text {st }}$ stage & Before & 61.6 & 51.44 & 48.3 & 59.64 & 49.69 & 46.08 \\
\hline & & After & 40.6 & 26.28 & 21.36 & 41.64 & 23.73 & 19.42 \\
\hline & & $\%$ diff & $-34.09 * * *$ & $-48.91^{* * *}$ & $-55.77 * * *$ & $-30.18 * * *$ & $-52.24^{* * *}$ & $-57.85^{* * *}$ \\
\hline & $2^{\text {nd }}$ stage & Before & 19.38 & 18.28 & 16.53 & 19.07 & 18.15 & 16.43 \\
\hline & & After & 13.89 & 11.23 & 8.77 & 12.27 & 10.34 & 8.67 \\
\hline & & $\%$ diff & $-28.32^{* * *}$ & $-38.56^{* * *}$ & $-46.94^{* * *}$ & $-35.65 * * *$ & $-43.03^{* * *}$ & $-47.23^{* * *}$ \\
\hline \multirow[t]{6}{*}{ Quoted Depth } & $1^{\text {st }}$ stage & Before & 895.81 & 1131.34 & 1144.93 & 995.16 & 1161.11 & 1401.83 \\
\hline & & After & 378.81 & 378.37 & 413.04 & 383.21 & 385.44 & 411.9 \\
\hline & & $\%$ diff & $-57.71 * * *$ & $-66.55^{* * *}$ & $-63.92^{* * *}$ & $-61.49 * * *$ & $-66.8^{* * *}$ & $-70.61^{* * *}$ \\
\hline & $2^{\text {nd }}$ stage & Before & 861.63 & 1095.07 & 1352.92 & 908.39 & 1156.35 & 1371.55 \\
\hline & & After & 293.22 & 347.31 & 412.97 & 364.89 & 392.07 & 426.51 \\
\hline & & $\%$ diff & $-65.96^{* * *}$ & $-68.28 * * *$ & $-69.47^{* * *}$ & $-59.83^{* * *}$ & $-66.09 * * *$ & $-68.90^{* * *}$ \\
\hline \multirow[t]{6}{*}{ Log Quote Slope } & $1^{\text {st }}$ stage & Before & 0.056 & 0.043 & 0.042 & 0.053 & 0.041 & 0.039 \\
\hline & & After & 0.044 & 0.028 & 0.024 & 0.046 & 0.025 & 0.022 \\
\hline & & $\%$ diff & $-21.42^{* * *}$ & $-34.88 * * *$ & $-42.85^{* * *}$ & $-13.2^{* * *}$ & $-39.02^{* * *}$ & $-43.58 * * *$ \\
\hline & $2^{\text {nd }}$ stage & Before & 0.017 & 0.016 & 0.013 & 0.017 & 0.015 & 0.013 \\
\hline & & After & 0.015 & 0.013 & 0.009 & 0.013 & 0.011 & 0.009 \\
\hline & & $\%$ diff & $-11.76^{* * *}$ & $-18.75^{* * *}$ & $-30.76^{* * *}$ & $-23.52^{* * *}$ & $-26.66^{* * *}$ & $-30.76^{* * *}$ \\
\hline \multirow[t]{6}{*}{ Effective Half Spread } & $1^{\text {st }}$ stage & Before & 42.08 & 35.75 & 32.97 & 39.89 & 34.25 & 30.33 \\
\hline & & After & 21.73 & 14.76 & 13.68 & 22.63 & 14.86 & 12.75 \\
\hline & & $\%$ diff & $-48.36^{* * *}$ & $-58.71^{* * *}$ & $-58.50 * * *$ & $-43.26^{* * *}$ & $-56.61^{* * *}$ & $-57.96^{* * *}$ \\
\hline & $2^{\text {nd }}$ stage & Before & 16.89 & 15.85 & 13.31 & 16.7 & 15.57 & 12.89 \\
\hline & & After & 9.54 & 7.52 & 5.26 & 8.72 & 7.32 & 5 \\
\hline & & $\%$ diff & $-43.51^{* * *}$ & $-52.55^{* * *}$ & $-60.48^{* * *}$ & $-47.78^{* * *}$ & $-52.98 * * *$ & $-61.21^{* * *}$ \\
\hline
\end{tabular}

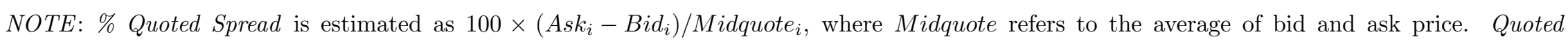
Depth refers to the average number of contracts at the ask and bid price, estimated in 5-minute intervals. Log Quote Slope is estimated as $\left(\right.$ Ask $_{i}$ Bid $\left._{i}\right) /\left(\log \left(\right.\right.$ Volume $\left._{a s k, i}\right)+\log \left(\right.$ Volume $\left.\left._{b i d, i}\right)\right)$, \% Effective Half Spread is estimated as $200 \times$ D $\times\left(\right.$ Price $_{i}-$ Midquote $\left._{i}\right) /$ Midquote $_{i}$, where D refers to a trade indicator dummy that takes the value of -1 is the trade is classified as a sell and +1 if it is classified as a buy. The first stage refers to the period around the first implementation of PBTS (June 02, 2009) and the second stage refers to the dates around the second implementation of PBTS (April 1, 2010). Before (after) refers to the 150-day period before (after) the implementation of PBTS. For calls, we define DOTM contracts with moneyness smaller than 0.9. OTM contracts with moneyness larger than or equal to 0.9 but smaller than 1.00 and ITM contracts with moneyness between or equal to 1.00 and 1.10 . The opposite classification is used for puts. $*, * *, * * *$ denote significance at $10 \%, 5 \%$ and $1 \%$ levels, respectively. 
Table 2: Realized Spread and Price Impact

\begin{tabular}{|c|c|c|c|c|c|c|c|c|}
\hline & & & \multicolumn{3}{|c|}{ Calls } & \multicolumn{3}{|c|}{ Puts } \\
\hline & & & DOTM & OTM & ITM & DOTM & OTM & ITM \\
\hline Price Impact & $1^{\text {st }}$ stage & Before & 24.84 & 24.65 & 28.81 & 23.97 & 23.04 & 22.59 \\
\hline \multirow{11}{*}{ Realized Spread } & & After & 10.51 & 9.11 & 7.1 & 10.15 & 8.47 & 9.08 \\
\hline & & $\%$ diff & $-57.68^{* * *}$ & $-63.04^{* * *}$ & -75.35 & $-57.65 * * *$ & $-63.23^{* * *}$ & -59.8 \\
\hline & $2^{\text {nd }}$ stage & Before & 10.88 & 11.15 & 9.31 & 11.24 & 11.34 & 9.45 \\
\hline & & After & 5.61 & 5.27 & 3.68 & 5.24 & 5.29 & 3.35 \\
\hline & & $\%$ diff & $-48.43^{* * *}$ & $-52.73^{* * *}$ & $-60.47^{* * *}$ & $-53.38 * * *$ & $-53.35 * * *$ & $-64.55^{* * *}$ \\
\hline & $1^{\text {st }}$ stage & Before & 16.18 & 13.4 & 7.06 & 15.04 & 12.45 & 11.71 \\
\hline & & After & 6.42 & 3.61 & 2.96 & 6.88 & 3.69 & 1.01 \\
\hline & & $\%$ diff & $-60.32^{* * *}$ & $-73.05^{* * *}$ & $-58.07^{* *}$ & $-54.25 * * *$ & $-70.36^{* * *}$ & -91.37 \\
\hline & $2^{\text {nd }}$ stage & Before & 5.41 & 4.12 & 3.72 & 4.78 & 3.89 & 3.38 \\
\hline & & After & 2.82 & 1.67 & 0.96 & 2.38 & 1.28 & 1.1 \\
\hline & & $\%$ diff & $-47.87 * * *$ & -59.46 & -74.19 & $-50.20 * * *$ & $-67.09 * *$ & -67.45 \\
\hline
\end{tabular}

NOTE: $\%$ Realized spread is estimated as $200 \times D \times\left(\right.$ Price $_{i}-$ Midquote $\left._{i+1}\right) /$ Midquote $_{i}$, where $D$ refers to a trade indicator dummy that takes the value of -1 is the trade is classified as a sell and +1 if it is classified as a buy. \% Price impact is estimated as $200 \times D \times\left(\right.$ Midquote $_{i+1}-$ Midquote $\left._{i}\right) /$ Midquote $_{i}$. The first stage refers to the period around the first implementation of PBTS (June 02, 2009) and the second stage refers to the dates around the second implementation of PBTS (April 1, 2010). Before (after) refers to the 150-day period before (after) the implementation of PBTS. For calls, we define DOTM contracts with moneyness smaller than 0.9, OTM contracts with moneyness larger than or equal to 0.9 but smaller than 1.00 and ITM contracts with moneyness between or equal to 1.00 and 1.10 . The opposite classification is used for puts. *, **, *** denote significance at $10 \%, 5 \%$ and $1 \%$ levels, respectively. 
Table 3: Trading Activity and Volatility

\begin{tabular}{|c|c|c|c|c|c|c|c|c|}
\hline & & & \multicolumn{3}{|c|}{ Calls } & \multicolumn{3}{|c|}{ Puts } \\
\hline & & & DOTM & OTM & ITM & DOTM & OTM & ITM \\
\hline \multirow[t]{6}{*}{ Traded Volume } & $1^{\text {st }}$ stage & Before & 11365.52 & 3780.21 & 337.5 & 6063.52 & 1738.92 & 200.93 \\
\hline & & After & 17090.36 & 12100.3 & 770.85 & 14121.94 & 6549.01 & 402.69 \\
\hline & & $\%$ diff & $50.37 * * *$ & $220.09^{* * *}$ & $128.4^{* * *}$ & $132.9^{* * *}$ & $276.61^{* * *}$ & $100.41^{* * *}$ \\
\hline & $2^{\text {nd }}$ stage & Before & 5716.99 & 15974.12 & 5638.36 & 5200.63 & 9628.09 & 2954.12 \\
\hline & & After & 10318.66 & 24612.85 & 6387.93 & 12627.98 & 17212.51 & 4041.42 \\
\hline & & $\%$ diff & $80.49^{* * *}$ & $54.07 * * *$ & 13.29 & $142.81^{* * *}$ & $78.77^{* * *}$ & $36.8^{* * *}$ \\
\hline \multirow[t]{6}{*}{ Trades } & $1^{\text {st }}$ stage & Before & 247.32 & 80.56 & 7.97 & 136.25 & 42.62 & 6.57 \\
\hline & & After & 292.78 & 219.67 & 17.24 & 307.77 & 135.52 & 10.46 \\
\hline & & $\%$ diff & $18.38^{* *}$ & $172.67^{* * *}$ & $116.31^{* * *}$ & $125.88 * * *$ & $217.97^{* * *}$ & $59.20 * * *$ \\
\hline & $2^{\text {nd }}$ stage & Before & 164.97 & 465.75 & 144.65 & 142.35 & 303.47 & 97.96 \\
\hline & & After & 231.81 & 590.84 & 157.8 & 211.37 & 366.07 & 108.4 \\
\hline & & $\%$ diff & $40.51^{* * *}$ & $26.85^{* * *}$ & 9.09 & $48.48^{* * *}$ & $20.62^{* * *}$ & $10.65^{* * *}$ \\
\hline \multirow[t]{6}{*}{ Volatility } & $1^{\text {st }}$ stage & Before & 5.16 & 5.92 & 7.06 & 4.43 & 5.31 & 5.75 \\
\hline & & After & 4.57 & 4.42 & 4.2 & 4.35 & 4.14 & 4.15 \\
\hline & & $\%$ diff & $-11.43^{* * *}$ & $-25.33 * * *$ & $-40.50 * * *$ & $-1.80^{* *}$ & $-22.03^{* * *}$ & $-27.82^{*}$ \\
\hline & $2^{\text {nd }}$ stage & Before & 3.28 & 3.62 & 3.4 & 2.96 & 3.5 & 3.24 \\
\hline & & After & 2.1 & 2.48 & 2.18 & 1.93 & 2.29 & 2.07 \\
\hline & & $\%$ diff & $-35.97 * * *$ & $-31.49 * * *$ & $-35.88 * * *$ & $-34.79 * * *$ & $-34.57 * * *$ & $-36.11^{* * *}$ \\
\hline
\end{tabular}

NOTE: Traded Volume refers to the average volume per day, Trades refer to the total number of transactions per day and Volatility is estimated as the standard deviation of the absolute value of intraday 5-minute returns. The first stage refers to the period around the first implementation of PBTS (June 02, 2009) and the second stage refers to the dates around the second implementation of PBTS (April 1, 2010). Before (after) refers to the 150-day period before (after) the implementation of PBTS. For calls, we define DOTM contracts with moneyness smaller than 0.9, OTM contracts with moneyness larger than or equal to 0.9 but smaller than 1.00 and ITM contracts with moneyness between or equal to 1.00 and 1.10 . The opposite classification is used for puts. $*, * *, * * *$ denote significance at $10 \%, 5 \%$ and $1 \%$ levels, respectively. 
Table 4: Traded Liquidity by Transaction Frequency

\begin{tabular}{|c|c|c|c|c|c|c|c|c|}
\hline & & & \multicolumn{3}{|c|}{ Calls } & \multicolumn{3}{|c|}{ Puts } \\
\hline & & & DOTM & OTM & ITM & DOTM & OTM & ITM \\
\hline \multirow{6}{*}{ Low } & $1^{\text {st }}$ stage & Before & 43.39 & 33.82 & 32.85 & 40.59 & 38.95 & 37.14 \\
\hline & & After & 26.1 & 24.38 & 19.31 & 33.44 & 22.5 & 19.06 \\
\hline & & $\%$ diff & $-39.84 * * *$ & $-27.91^{* * *}$ & $-41.21^{* * *}$ & $-17.61^{* *}$ & $-42.23^{* * *}$ & $-48.68 * * *$ \\
\hline & $2^{\text {nd }}$ stage & Before & 20.36 & 20.39 & 17.96 & 20.31 & 20.62 & 15.34 \\
\hline & & After & 18.31 & 14.62 & 9.67 & 17.67 & 16.01 & 8.34 \\
\hline & & $\%$ diff & -10.06 & -28.29 & -46.15 & $-12.99^{*}$ & -22.35 & -45.63 \\
\hline \multirow[t]{6}{*}{ Medium } & $1^{\text {st }}$ stage & Before & 42.67 & 38.04 & 37.08 & 38.34 & 35.63 & 31.97 \\
\hline & & After & 25.6 & 17.95 & 11.2 & 24.02 & 16.6 & 10.48 \\
\hline & & $\%$ diff & $-40.00 * * *$ & $-52.81^{* * *}$ & $-69.79 * * *$ & $-37.35 * * *$ & $-53.41 * * *$ & $-67.21^{* * *}$ \\
\hline & $2^{\text {nd }}$ stage & Before & 17.42 & 17.18 & 13.92 & 17.36 & 16.47 & 13.23 \\
\hline & & After & 11.64 & 9.52 & 7.49 & 10.8 & 8.87 & 6.89 \\
\hline & & $\%$ diff & $-33.18 * * *$ & $-44.58 * * *$ & -46.19 & $-37.78 * * *$ & $-46.14^{* *}$ & -47.92 \\
\hline \multirow[t]{6}{*}{ High } & $1^{\text {st }}$ stage & Before & 41.85 & 35.38 & 31.1 & 40.19 & 33.74 & 28.76 \\
\hline & & After & 20.26 & 13.52 & 12.9 & 21.09 & 14.03 & 13.46 \\
\hline & & $\%$ diff & $-51.58 * * *$ & $-61.78^{* * *}$ & $-58.52^{* * *}$ & $-47.52^{* * *}$ & $-58.41^{* * *}$ & $-53.19 * * *$ \\
\hline & $2^{\text {nd }}$ stage & Before & 16.62 & 15.38 & 13.18 & 16.27 & 15.18 & 12.8 \\
\hline & & After & 8.33 & 6.71 & 4.87 & 7.45 & 6.63 & 4.7 \\
\hline & & $\%$ diff & $-49.87 * * *$ & $-56.37 * * *$ & $-63.05 * * *$ & $-54.21 * * *$ & $-56.32 * * *$ & $-63.28^{* *}$ \\
\hline
\end{tabular}

NOTE: Traded Liquidity refers to the effective spread, estimated as $200 \times D \times\left(\right.$ Price $_{i}-$ Midquote $\left._{i}\right) /$ Midquote $_{i}$, where $D$ refers to a trade indicator dummy that takes the value of -1 is the trade is classified as a sell and +1 if it is classified as a buy. Low, medium and high refer to daily transaction frequency. Low refers to the first quartile and High to the fourth quartile. Medium refers to the second and third quartile. The first stage refers to the period around the first implementation of PBTS (June 02, 2009) and the second stage refers to the dates around the second implementation of PBTS (April 1, 2010). Before (after) refers to the 150-day period before (after) the implementation of PBTS. For calls, we define DOTM contracts with moneyness smaller than 0.9. OTM contracts with moneyness larger than or equal to 0.9 but smaller than 1.00 and ITM contracts with moneyness between or equal to 1.00 and 1.10 . The opposite classification is used for puts. $*, * *, * * *$ denote significance at $10 \%, 5 \%$ and $1 \%$ levels, respectively. 
Table 5: Quoted Liquidity by Underlying Volatility

\begin{tabular}{|c|c|c|c|c|c|c|c|c|}
\hline & & & \multicolumn{3}{|c|}{ Calls } & \multicolumn{3}{|c|}{ Puts } \\
\hline & & & DOTM & OTM & ITM & DOTM & OTM & ITM \\
\hline \multirow{6}{*}{ Low } & $1^{\text {st }}$ stage & Before & 0.054 & 0.041 & 0.039 & 0.049 & 0.039 & 0.04 \\
\hline & & After & 0.046 & 0.026 & 0.016 & 0.048 & 0.023 & 0.015 \\
\hline & & $\%$ diff & $-14.81^{*}$ & $-36.58 * * *$ & $-58.97 * * *$ & -2.04 & $-41.02^{* * *}$ & $-62.5^{* * *}$ \\
\hline & $2^{\text {nd }}$ stage & Before & 0.019 & 0.015 & 0.012 & 0.017 & 0.014 & 0.012 \\
\hline & & After & 0.017 & 0.011 & 0.008 & 0.013 & 0.01 & 0.008 \\
\hline & & $\%$ diff & $-10.52^{*}$ & $-26.66^{* * *}$ & -33.33 & $-23.52^{* * *}$ & $-28.57 * * *$ & -33.33 \\
\hline \multirow[t]{6}{*}{ Medium } & $1^{\text {st }}$ stage & Before & 0.062 & 0.049 & 0.037 & 0.062 & 0.046 & 0.034 \\
\hline & & After & 0.048 & 0.035 & 0.016 & 0.052 & 0.031 & 0.017 \\
\hline & & $\%$ diff & $-22.58 * * *$ & $-28.57 * * *$ & $-56.75 * * *$ & $-16.12^{* * *}$ & $-32.60 * * *$ & $-50.00 * * *$ \\
\hline & $2^{\text {nd }}$ stage & Before & 0.021 & 0.019 & 0.018 & 0.02 & 0.019 & 0.018 \\
\hline & & After & 0.019 & 0.018 & 0.016 & 0.017 & 0.016 & 0.017 \\
\hline & & $\%$ diff & -9.52 & $-5.26^{* * *}$ & -11.11 & $-15 * * *$ & $-15.78^{* * *}$ & -5.55 \\
\hline \multirow[t]{6}{*}{ High } & $1^{\text {st }}$ stage & Before & 0.054 & 0.045 & 0.048 & 0.05 & 0.043 & 0.042 \\
\hline & & After & 0.04 & 0.028 & 0.036 & 0.04 & 0.025 & 0.028 \\
\hline & & $\%$ diff & $-25.92^{* * *}$ & $-37.77^{* * *}$ & $-25.00 * * *$ & $-20.00^{* * *}$ & $-41.86^{* * *}$ & $-33.33^{* * *}$ \\
\hline & $2^{\text {nd }}$ stage & Before & 0.015 & 0.015 & 0.014 & 0.015 & 0.014 & 0.013 \\
\hline & & After & 0.013 & 0.011 & 0.009 & 0.01 & 0.01 & 0.009 \\
\hline & & $\%$ diff & -13.33 & $-26.66^{* * *}$ & $-35.71 * * *$ & $-33.33 * * *$ & $-28.57 * * *$ & $-30.76^{* * *}$ \\
\hline
\end{tabular}

NOTE: Quoted Liquidity refers to log quote slope estimated as $\left(A s k_{i}-B i d_{i}\right) /\left(\log \left(\operatorname{Volume}_{a s k, i}\right)+\log \left(\operatorname{Volume}_{b i d, i}\right)\right)$. We use the range estimator as a measure of the underlying market volatility. We use the period before the implementation of the tick size changes to classify tickers based on liquidity. The first stage refers to the period around the first implementation of PBTS (June 02, 2009) and the second stage refers to the dates around the second implementation of PBTS (April 1, 2010). Before (after) refers to the 150-day period before (after) the implementation of PBTS. For calls, we define DOTM contracts with moneyness smaller than 0.9, OTM contracts with moneyness larger than or equal to 0.9 but smaller than 1.00 and ITM contracts with moneyness between or equal to 1.00 and 1.10 . The opposite classification is used for puts. *, **, *** denote significance at $10 \%$, $5 \%$ and $1 \%$ levels, respectively. 
Table 6: \% Price Improvement

\begin{tabular}{cccccccc}
\hline \hline & & & Calls & & & Puts \\
\hline \multirow{2}{*}{$1^{\text {st }}$ stage } & & DOTM & OTM & ITM & DOTM & OTM & ITM \\
& Before & 4.2 & 4.53 & 11.55 & 4.39 & 4.45 & 18.23 \\
& After & 15.7 & 15.17 & 17.7 & 15.77 & 16.16 & 17.67 \\
\multirow{2}{*}{$2^{\text {nd }}$ stage } & $\%$ diff & $273.80^{* * *}$ & $234.87^{* * *}$ & $53.24^{*}$ & $259.22^{* * *}$ & $263.14^{* * *}$ & $-3.07^{* * *}$ \\
& Before & 5.42 & 6.07 & 5.8 & 5.43 & 6.53 & 6.16 \\
& After & 17.87 & 16.72 & 15.34 & 17.43 & 16.55 & 15.17 \\
& $\%$ diff & $229.70^{* * *}$ & $175.45^{* * *}$ & $164.48^{* * *}$ & $220.99^{* * *}$ & $153.44^{* * *}$ & $146.26^{* * *}$ \\
\hline
\end{tabular}

NOTE: For the calculation of \% Price Improvement we use the entire time series at the best bid and ask and for each subticker, we classify a new best bid or best ask as a price improvement when the new ask is smaller than the previous ask or the new bid is greater than the old bid.We follow this procedure separately for calls and puts and across moneyness levels. We subsequently calculate the percentage of quote improvements per subticker, per day.The first stage refers to the period around the first implementation of PBTS (June 02, 2009) and the second stage refers to the dates around the second implementation of PBTS (April 1, 2010). Before (after) refers to the 150-day period before (after) the implementation of PBTS. For calls, we define DOTM contracts with moneyness smaller than 0.9, OTM contracts with moneyness larger than or equal to 0.9 but smaller than 1.00 and ITM contracts with moneyness between or equal to 1.00 and 1.10 . The opposite classification is used for puts. *, **, *** denote significance at $10 \%$, $5 \%$ and $1 \%$ levels, respectively. 
Table 7: DID Quoted Spread and Quoted Depth

\begin{tabular}{|c|c|c|c|c|c|c|c|c|c|c|c|c|}
\hline & \multicolumn{6}{|c|}{ Spread } & \multicolumn{6}{|c|}{ Depth } \\
\hline & \multicolumn{3}{|c|}{$1^{\text {st }}$ stage } & \multicolumn{3}{|c|}{$2^{\text {nd }}$ stage } & \multicolumn{3}{|c|}{$1^{\text {st }}$ stage } & \multicolumn{3}{|c|}{$2^{\text {nd }}$ stage } \\
\hline & DOTM & OTM & ITM & DOTM & OTM & ITM & DOTM & OTM & ITM & DOTM & OTM & ITM \\
\hline \multirow[t]{2}{*}{ Constant } & $17.91^{* * *}$ & $13.08^{* * *}$ & $7.06^{* * *}$ & $13.65^{* * *}$ & $13.97^{* * *}$ & $10.00^{* * *}$ & $-1671^{* * *}$ & $-2667^{* * *}$ & $-3345^{* * *}$ & $-1635^{* * *}$ & $-2546^{* * *}$ & $-3381 * * *$ \\
\hline & $(23.46)$ & $(35.82)$ & (15.91) & $(23.22)$ & $(43.27)$ & $(34.44)$ & $(-16.89)$ & $(-36.24)$ & $(-41.82)$ & $(-23.10)$ & $(-38.54)$ & $(-39.35)$ \\
\hline \multirow[t]{2}{*}{ Treatment } & $27.77^{* * *}$ & $23.69 * * *$ & $12.42^{* * *}$ & $3.65^{* * *}$ & $3.64^{* * *}$ & $3.10^{* * *}$ & $201^{* * *}$ & $281^{* * *}$ & $-539 * * *$ & $238^{* * *}$ & $233^{* * *}$ & $108^{* * *}$ \\
\hline & $(104.73)$ & $(72.25)$ & $(10.70)$ & $(36.16)$ & $(60.76)$ & $(44.34)$ & (16.19) & $(14.70)$ & $(-5.96)$ & (15.67) & $(21.04)$ & $(5.61)$ \\
\hline \multirow[t]{2}{*}{ Post } & $-1.33^{* * *}$ & $-0.56^{* * *}$ & $-0.79^{* * *}$ & $1.78^{* * *}$ & $0.89 * * *$ & $0.22^{* * *}$ & 19.64 & -8.00 & $69.50^{* * *}$ & $-109^{* * *}$ & $-75.4^{* * *}$ & $161.22^{* * *}$ \\
\hline & $(-11.38)$ & $(-8.11)$ & $(-11.42)$ & $(20.94)$ & (19.38) & $(4.28)$ & $(0.64)$ & $(-0.34)$ & (3.01) & $(-4.54)$ & $(-3.46)$ & $(5.01)$ \\
\hline \multirow{2}{*}{$\begin{array}{l}\text { Treat } \times \\
\text { Post }\end{array}$} & $-30.95^{* * *}$ & $-28.04^{* * *}$ & $-24.91 * * *$ & $-10.04 * * *$ & $-10.03^{* * *}$ & $-9.08^{* * *}$ & $-553^{* * *}$ & $-878^{* * *}$ & $-1006^{* * *}$ & $-613^{* * *}$ & $-751^{* * *}$ & $-1004^{* * *}$ \\
\hline & $(-120.45)$ & $(-96.68)$ & $(-20.79)$ & $(-64.57)$ & $(-114.74)$ & $(-100.78)$ & $(-23.00)$ & $(-32.63)$ & $(-10.99)$ & $(-27.48)$ & $(-39.93)$ & $(-29.48)$ \\
\hline \multirow[t]{2}{*}{ Volatility } & $0.38^{* * *}$ & $0.22^{* * *}$ & $0.18^{* * *}$ & $0.47^{* * *}$ & $0.31^{* * *}$ & $0.33^{* * *}$ & $-32.18 * * *$ & $-25.08^{* * *}$ & $-20.69 * * *$ & $-24.65^{* * *}$ & $-35.15^{* * *}$ & $-46.21^{* * *}$ \\
\hline & $(26.36)$ & $(29.99)$ & $(29.58)$ & $(23.42)$ & $(46.00)$ & $(49.89)$ & $(-23.23)$ & $(-27.12)$ & $(-17.29)$ & $(-22.54)$ & $(-33.22)$ & $(-24.88)$ \\
\hline \multirow[t]{2}{*}{$1 / \operatorname{Pr}$} & $2.82^{* * *}$ & $2.48^{* * *}$ & $4.22^{* * *}$ & $4.13^{* * *}$ & $3.75^{* * *}$ & $3.16^{* * *}$ & $1.24^{* * *}$ & $3.15^{* * *}$ & $226.28^{* * *}$ & $74.63^{* * *}$ & $94.37 * * *$ & $241.21^{* * *}$ \\
\hline & $(97.82)$ & $(65.24)$ & $(22.37)$ & $(95.79)$ & $(124.41)$ & $(70.13)$ & $(2.86)$ & $(3.95)$ & (15.89) & $(20.64)$ & $(24.54)$ & $(25.14)$ \\
\hline \multirow[t]{2}{*}{ Volume } & $0.90 * * *$ & $1.92^{* * *}$ & $1.89 * * *$ & $-0.98^{* * *}$ & $0.16^{* * *}$ & $0.96^{* * *}$ & & & & & & \\
\hline & $(8.79)$ & $(40.27)$ & $(41.63)$ & $(-7.45)$ & $(3.60)$ & $(22.04)$ & & & & & & \\
\hline \multirow[t]{2}{*}{ Under $M V$} & $-1.71^{* * *}$ & $-1.99 * * *$ & $-1.69 * * *$ & $-0.47 * * *$ & $-1.21^{* * *}$ & $-1.33^{* * *}$ & $248.16^{* * *}$ & $380.91^{* * *}$ & $441.76^{* * *}$ & $229.32 * * *$ & $338.65^{* * *}$ & $456.81^{* * *}$ \\
\hline & $(-20.63)$ & $(-46.14)$ & $(-49.78)$ & $(-5.31)$ & $(-30.42)$ & $(-36.97)$ & $(26.21)$ & $(55.62)$ & $(60.63)$ & $(31.71)$ & $(52.04)$ & $(54.55)$ \\
\hline \multirow[t]{2}{*}{$P B A S$} & $1.92^{* * *}$ & $1.65^{* * *}$ & $1.20^{* * *}$ & $4.15^{* * *}$ & $4.02^{* * *}$ & $3.90^{* * *}$ & $-13.40^{* * *}$ & $13.43^{* * *}$ & $18.65^{* * *}$ & $22.62^{* * *}$ & $206.32^{* * *}$ & $-60.84^{* * *}$ \\
\hline & $(2.70)$ & $(4.59)$ & $(4.36)$ & $(4.48)$ & $(8.11)$ & $(9.63)$ & $(-0.14)$ & $(0.19)$ & $(0.29)$ & $(0.26)$ & $(2.90)$ & $(-0.73)$ \\
\hline \multirow[t]{2}{*}{ UnderVolt } & $-0.23^{* * *}$ & $-0.23^{* * *}$ & $-0.16^{* * *}$ & 0.07 & 0.01 & $<0.01$ & $64.68^{* * *}$ & $78.16^{* * *}$ & $73.99 * * *$ & $57.56^{* * *}$ & $97.85^{* * *}$ & $85.37^{* * *}$ \\
\hline & $(-7.37)$ & $(-13.18)$ & $(-12.07)$ & (1.63) & $(0.61)$ & $(0.05)$ & (11.30) & $(16.15)$ & $(14.71)$ & $(8.15)$ & (14.16) & $(10.26)$ \\
\hline$R^{2}$ & 0.74 & 0.75 & 0.46 & 0.36 & 0.45 & 0.41 & 0.27 & 0.35 & 0.40 & 0.37 & 0.39 & 0.45 \\
\hline
\end{tabular}

NOTE: Spread refers to quoted spread and depth refers to quoted depth. Treatment is a dummy variable that takes the value of 1 for options that are affected by the implementation of the PBTS. Post is a dummy variable that takes the value of 1 for the dates after the implementation of the PBTS. Volatility is estimated as the absolute value of intraday 5-minute returns. Pr refers to option price, Volume is the natural logarithm of trading volume per interval, $U n d e r M V$ refers to the natural logarithm of market capitalization of the underlying asset, $P B A S$ refers to the underlying percentage bid-ask spread and $U n d e r V$ olt refers to the underlying volatility estimated used the range estimator. The first stage refers to the period around the first implementation of PBTS (June 02, 2009) and the second stage refers to the dates around the second implementation of PBTS (April 1, 2010). For calls, we define DOTM contracts with moneyness smaller than 0.9, OTM contracts with moneyness between 0.9 and 1.00 and ITM contracts with moneyness between or equal to 1.00 and 1.10 . The opposite classification is used for puts. T-statistics are in parentheses. *, **, *** denote significance at $10 \%, 5 \%$ and $1 \%$ levels, respectively. 
Table 8: DID Traded and Quoted Liquidity

\begin{tabular}{|c|c|c|c|c|c|c|c|c|c|c|c|c|}
\hline & \multicolumn{6}{|c|}{ Spread } & \multicolumn{6}{|c|}{ Depth } \\
\hline & \multicolumn{3}{|c|}{$1^{\text {st }}$ stage } & \multicolumn{3}{|c|}{$2^{\text {nd }}$ stage } & \multicolumn{3}{|c|}{$1^{\text {st }}$ stage } & \multicolumn{3}{|c|}{$2^{\text {nd }}$ stage } \\
\hline & DOTM & OTM & ITM & DOTM & OTM & ITM & DOTM & OTM & ITM & DOTM & OTM & ITM \\
\hline Constant & $\begin{array}{l}17.31^{* * *} \\
(16.94)\end{array}$ & $\begin{array}{l}14.90^{* * *} \\
(17.47)\end{array}$ & $\begin{array}{l}5.23 * * * \\
(8.85)\end{array}$ & $\begin{array}{l}14.71^{* * *} \\
(11.12)\end{array}$ & $\begin{array}{l}14.09^{* * *} \\
(19.94)\end{array}$ & $\begin{array}{l}5.47^{* * *} \\
(14.83)\end{array}$ & $\begin{array}{l}0.04^{* * *} \\
(31.27)\end{array}$ & $\begin{array}{l}0.02^{* * *} \\
(54.59)\end{array}$ & $\begin{array}{l}0.01^{* * *} \\
(31.10)\end{array}$ & $\begin{array}{l}0.02^{* * *} \\
(22.64)\end{array}$ & $\begin{array}{l}0.02^{* * *} \\
(50.88)\end{array}$ & $\begin{array}{l}0.01^{* * *} \\
(49.92)\end{array}$ \\
\hline Treatment & $\begin{array}{l}23.36^{* * *} \\
(56.63)\end{array}$ & $\begin{array}{l}20.35^{* * *} \\
(43.81)\end{array}$ & $\begin{array}{l}10.53^{* * *} \\
(6.39)\end{array}$ & $\begin{array}{l}3.89 * * * \\
(9.39)\end{array}$ & $\begin{array}{l}3.75^{* * *} \\
(18.48)\end{array}$ & $\begin{array}{l}2.91^{* * *} \\
(20.08)\end{array}$ & $\begin{array}{l}2.1 \mathrm{E}-2 * * * \\
(53.26)\end{array}$ & $\begin{array}{l}1.6 \mathrm{E}-2^{* * *} \\
(40.81)\end{array}$ & $\begin{array}{l}9.0 \mathrm{E}-2 * * * \\
(6.76)\end{array}$ & $\begin{array}{l}2.0 \mathrm{E}-2 * * * \\
(14.43)\end{array}$ & $\begin{array}{l}2.0 \mathrm{E}-2 * * * \\
(30.09)\end{array}$ & $\begin{array}{l}2.0 \mathrm{E}-2^{* * *} \\
(29.49)\end{array}$ \\
\hline Post & $\begin{array}{l}-1.32^{* * *} \\
(-5.17)\end{array}$ & $\begin{array}{l}-0.60 * * * \\
(-3.29)\end{array}$ & $\begin{array}{l}-0.01 \\
(-0.35)\end{array}$ & $\begin{array}{l}-0.09 \\
(-0.25)\end{array}$ & $\begin{array}{l}-0.07 \\
(-0.47)\end{array}$ & $\begin{array}{l}0.01 \\
(0.30)\end{array}$ & $\begin{array}{l}-2 \mathrm{E}-2 * * * \\
(-8.31)\end{array}$ & $\begin{array}{l}0.001^{* * *} \\
(2.96)\end{array}$ & $\begin{array}{l}-1 \mathrm{E}-2 * * * \\
(-8.73)\end{array}$ & $\begin{array}{l}3 \mathrm{E}-2 * * * \\
(15.09)\end{array}$ & $\begin{array}{l}1 \mathrm{E}-2^{* * *} \\
(15.03)\end{array}$ & $\begin{array}{l}0.001^{\text {*** }} \\
(3.56)\end{array}$ \\
\hline $\begin{array}{l}\text { Treat } \times \\
\text { Post }\end{array}$ & $-23.90^{* * *}$ & $-22.37^{* * *}$ & $-17.02^{* * *}$ & $-8.01 * * *$ & $-8.53^{* * *}$ & $-8.39^{* * *}$ & $-2 \mathrm{E}-2 * * *$ & $-2 \mathrm{E}-2 * * *$ & $-1 \mathrm{E}-2 * * *$ & $-5 \mathrm{E}-2 * * *$ & $-6 \mathrm{E}-2 * * *$ & $-6 \mathrm{E}-2 * * *$ \\
\hline & $(-57.69)$ & $(-45.58)$ & $(-12.40)$ & $(-18.18)$ & $(-40.97)$ & $(-66.45)$ & $(-53.00)$ & $(-57.60)$ & $(-10.63)$ & $(-29.34)$ & $(-56.41)$ & $(-77.59)$ \\
\hline Volatility & $\begin{array}{l}0.22^{* * *} \\
(4.77)\end{array}$ & $\begin{array}{l}0.16^{* * *} \\
(4.88)\end{array}$ & $\begin{array}{l}-0.01 \\
(-1.39)\end{array}$ & $\begin{array}{l}0.40^{* * *} \\
(5.80)\end{array}$ & $\begin{array}{l}0.35^{* * *} \\
(9.28)\end{array}$ & $\begin{array}{l}0.05^{* * *} \\
(4.39)\end{array}$ & $\begin{array}{l}1.0 \mathrm{E}-2 * * * \\
(29.12)\end{array}$ & $\begin{array}{l}0.001^{* * * *} \\
(23.73)\end{array}$ & $\begin{array}{l}0.001^{* * *} \\
(21.67)\end{array}$ & $\begin{array}{l}1.0 \mathrm{E}-2 * * * \\
(17.02)\end{array}$ & $\begin{array}{l}0.001^{* * *} \\
(33.65)\end{array}$ & $\begin{array}{l}0.0 \mathrm{E}-2^{* * *} \\
(36.31)\end{array}$ \\
\hline $1 / \operatorname{Pr}$ & $\begin{array}{l}1.23^{* * *} \\
(30.12)\end{array}$ & $\begin{array}{l}1.12^{* * *} \\
(25.20)\end{array}$ & $\begin{array}{l}2.69^{* * *} \\
(8.35)\end{array}$ & $\begin{array}{l}2.34^{* * *} \\
(13.91)\end{array}$ & $\begin{array}{l}2.33^{* * *} \\
(23.33)\end{array}$ & $\begin{array}{l}2.40^{* * *} \\
(22.57)\end{array}$ & $\begin{array}{l}3.0 \mathrm{E}-2 * * * \\
(77.24)\end{array}$ & $\begin{array}{l}2.0 \mathrm{E}-2^{* * * *} \\
(48.44)\end{array}$ & $\begin{array}{l}4.0 \mathrm{E}-2^{* * *} \\
(17.83)\end{array}$ & $\begin{array}{l}4.0 \mathrm{E}-2^{* * *} \\
(58.77)\end{array}$ & $\begin{array}{l}3.0 \mathrm{E}-2^{* * *} \\
(89.38)\end{array}$ & $\begin{array}{l}2.0 \mathrm{E}-2^{* * *} \\
(57.65)\end{array}$ \\
\hline Volume & $\begin{array}{l}-0.76^{* * *} \\
(-7.74)\end{array}$ & $\begin{array}{l}-0.65^{* * *} \\
(-9.18)\end{array}$ & $\begin{array}{l}-0.22^{* * *} \\
(-7.79)\end{array}$ & $\begin{array}{l}-0.77^{* * *} \\
(-6.84)\end{array}$ & $\begin{array}{l}-0.87^{* * *} \\
(-14.58)\end{array}$ & $\begin{array}{l}-0.24^{* * *} \\
(-8.76)\end{array}$ & $\begin{array}{c}-4 \mathrm{E}-2 * * * \\
(-31.30)\end{array}$ & $\begin{array}{c}-2 \mathrm{E}-2^{* * *} \\
(-48.83)\end{array}$ & $\begin{array}{c}-1 \mathrm{E}-2^{* * *} \\
(-47.90)\end{array}$ & $\begin{array}{c}-2 \mathrm{E}-2 * * * \\
(-23.51)\end{array}$ & $\begin{array}{c}-2 \mathrm{E}-2 * * * \\
(-50.51)\end{array}$ & $\begin{array}{c}-2 \mathrm{E}-2^{* * *} \\
(-45.53)\end{array}$ \\
\hline Under $M V$ & $\begin{array}{l}-0.59 * * * \\
(-8.03)\end{array}$ & $\begin{array}{l}-0.38^{* * *} \\
(-7.35)\end{array}$ & $\begin{array}{l}0.01 \\
(0.77)\end{array}$ & $\begin{array}{l}-0.46^{* * *} \\
(-5.60)\end{array}$ & $\begin{array}{l}-0.14^{* * *} \\
(-3.70)\end{array}$ & $\begin{array}{l}0.09^{* * *} \\
(3.26)\end{array}$ & & & & & & \\
\hline$P B A S$ & $\begin{array}{l}0.53 \\
(0.55)\end{array}$ & $\begin{array}{l}1.38 \\
(1.39)\end{array}$ & $\begin{array}{l}-0.34 \\
(-0.95)\end{array}$ & $\begin{array}{l}1.55 \\
(0.93)\end{array}$ & $\begin{array}{l}1.07 \\
(1.12)\end{array}$ & $\begin{array}{l}0.42 \\
(1.25)\end{array}$ & $\begin{array}{l}5.0 \mathrm{E}-2^{* * * *} \\
(3.63)\end{array}$ & $\begin{array}{l}3.0 \mathrm{E}-2^{* * * *} \\
(5.72)\end{array}$ & $\begin{array}{l}2.0 \mathrm{E}-2^{* * *} \\
(5.89)\end{array}$ & $\begin{array}{l}7.0 \mathrm{E}-2^{* * * *} \\
(4.22)\end{array}$ & $\begin{array}{l}6.0 \mathrm{E}-2^{* * *} \\
(8.15)\end{array}$ & $\begin{array}{l}5.0 \mathrm{E}-02 \\
(10.21)\end{array}$ \\
\hline UnderVolt & $\begin{array}{l}-0.21^{* * *} \\
(-6.74)\end{array}$ & $\begin{array}{l}-0.19^{* * *} \\
(-4.90)\end{array}$ & $\begin{array}{l}0.02^{* *} \\
(2.46)\end{array}$ & $\begin{array}{l}-0.23^{* * *} \\
(-3.10)\end{array}$ & $\begin{array}{l}-0.25^{* * *} \\
(-5.90)\end{array}$ & $\begin{array}{l}0.02^{*} \\
(1.67)\end{array}$ & $\begin{array}{c}-1 \mathrm{E}-2 * * * \\
(-11.11)\end{array}$ & $\begin{array}{l}0.001^{* * *} \\
(10.37)\end{array}$ & $\begin{array}{l}0.001^{* * *} \\
(9.74)\end{array}$ & $\begin{array}{l}0.001^{* * *} \\
(3.44)\end{array}$ & $\begin{array}{l}0.001^{* * *} \\
(4.17)\end{array}$ & $\begin{array}{l}0.001^{* * *} \\
(1.18)\end{array}$ \\
\hline$R^{2}$ & 0.37 & 0.16 & 0.36 & 0.04 & 0.04 & 0.39 & 0.62 & 0.65 & 0.46 & 0.23 & 0.37 & 0.42 \\
\hline
\end{tabular}

NOTE: Traded liquidity refers to effective spread, estimated as $200 \times D \times\left(\right.$ Price $_{i}-$ Midquote $\left._{i}\right) /$ Midquote $_{i}$, where $D$ refers to a trade indicator dummy that takes the value of -1 if the trade is classified as a sell and +1 if it is classified as a buy. Quoted liquidity refers to log quote slope estimated as $\left(A_{s k_{i}}-B_{i d}\right) /\left(\log \left(\right.\right.$ Volume $\left._{a s k, i}\right)+\log \left(\right.$ Volume $\left.\left._{b i d, i}\right)\right)$. Treatment is a dummy variable that takes the value of 1 for options that are affected by the implementation of the PBTS. Post is a dummy variable that takes the value of 1 for the dates after the implementation of the PBTS. Volatility is estimated as the absolute value of intraday 5-minute returns. $P r$ refers to option price, Volume is the natural logarithm of trading volume per interval, $U n d e r M V$ refers to the natural logarithm of market capitalization of the underlying asset, $P B A S$ refers to the underlying percentage bid-ask spread and UnderVolt refers to the underlying volatility estimated used the range estimator. The first stage refers to the period around the first implementation of PBTS (June 02, 2009) and the second stage refers to the dates around the second implementation of PBTS (April 1, 2010). For calls, we define DOTM contracts with moneyness smaller than 0.9. OTM contracts with moneyness between 0.9 and 1.00 and ITM contracts with moneyness between or equal to 1.00 and 1.10 . The opposite classification is used for puts. T-statistics are in parentheses. $*, * *, * * *$ denote significance at $10 \%, 5 \%$ and $1 \%$ levels, respectively 
Figure 1: Quoted Spread and Depth Around the Tick Size Change
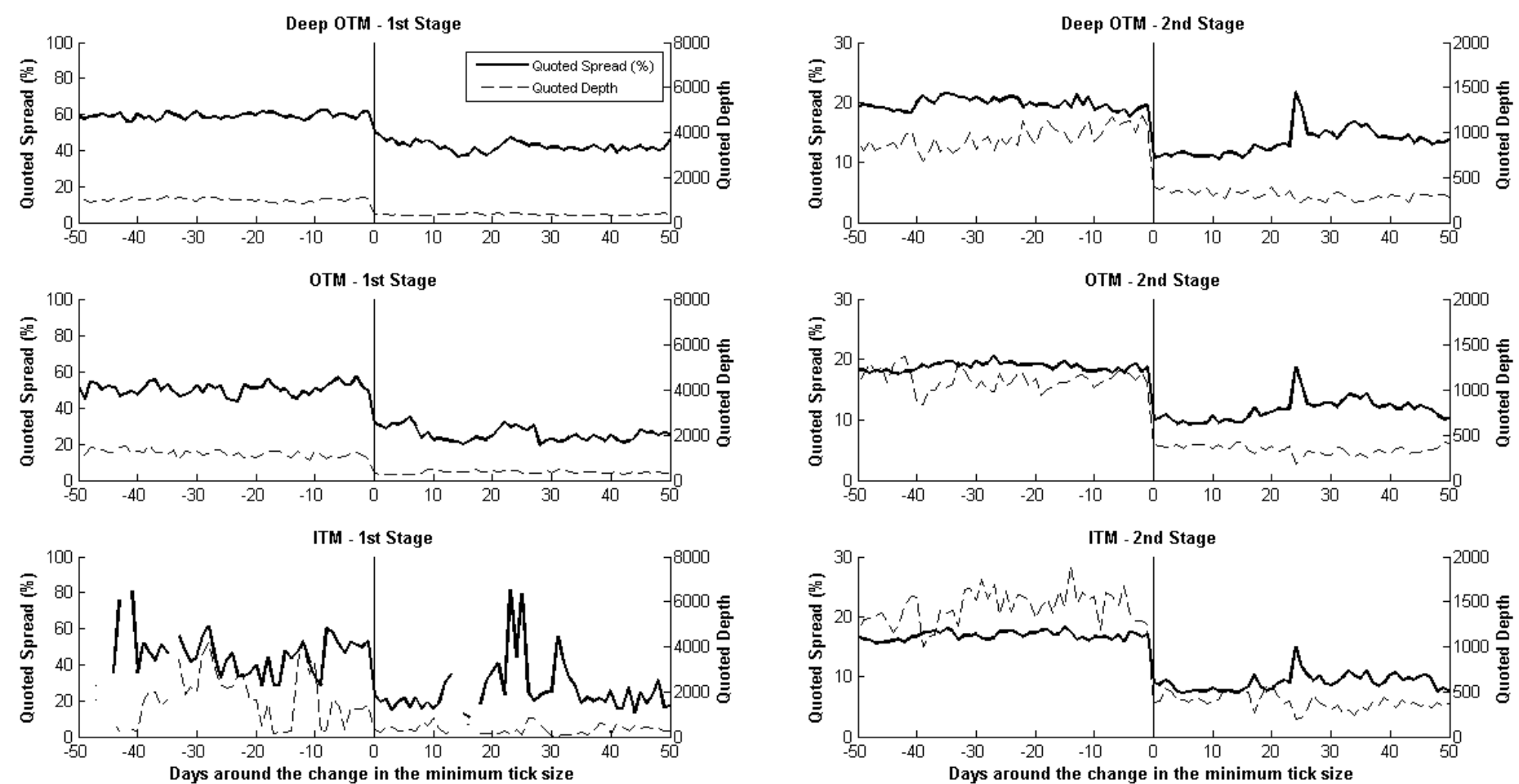

Notes: This Figure plots the average quoted spread and quoted depth for contracts trading around the implementation of the PBTS. The horizontal axis refers to days to and from the $1^{\text {st }}$ and $2^{\text {nd }}$ stage of PBTS. Due to space considerations, we only present the result for call contracts. 
Figure 2: Quoted and Traded Liquidity Around the Tick Size Change
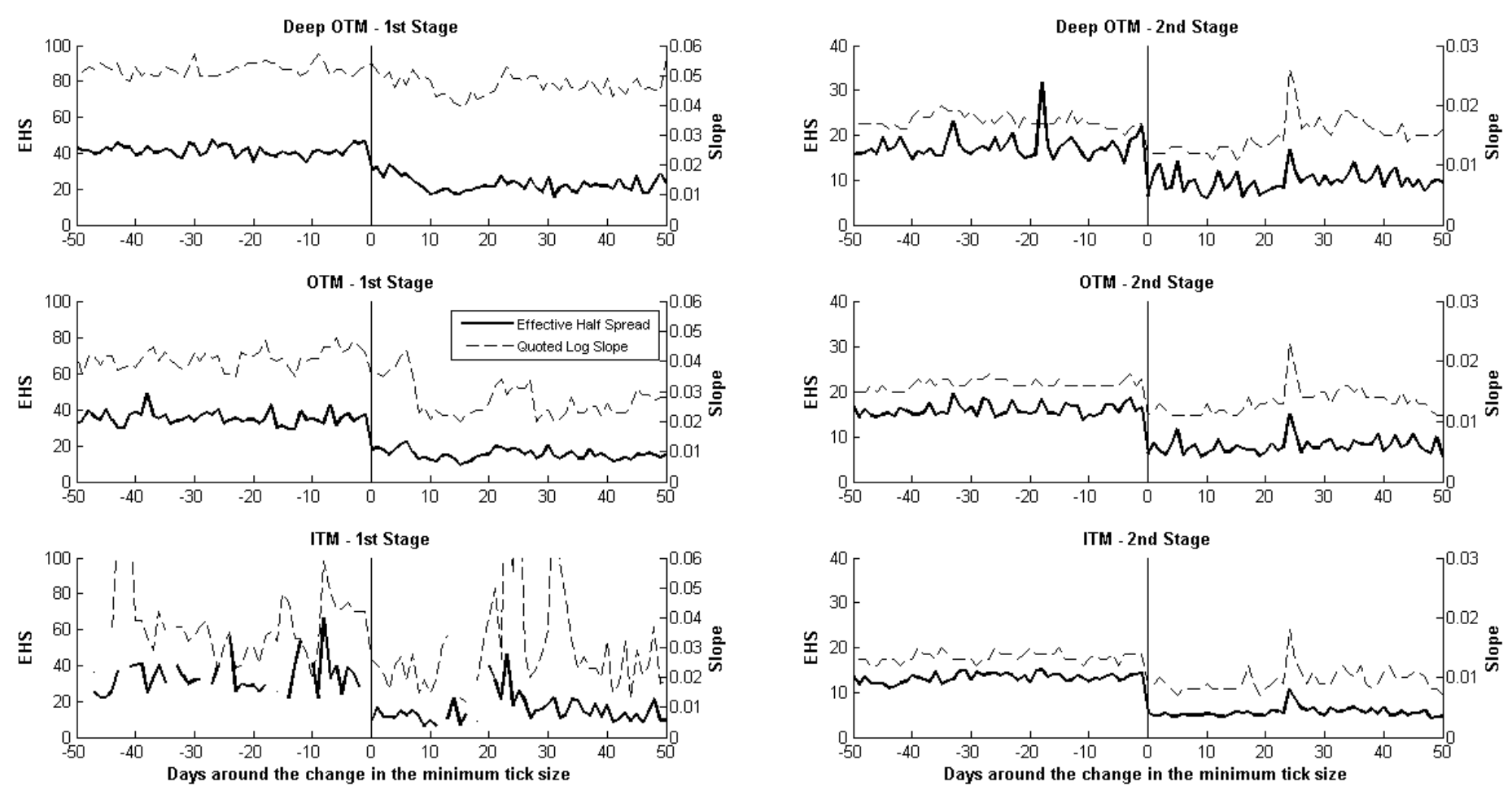

Notes: This Figure plots the average effective half spread (EHS) and quoted log slope (Slope) for contracts trading around the implementation of the PBTS. The horizontal axis refers to days to and from the $1^{\text {st }}$ and $2^{\text {nd }}$ stage of PBTS. Due to space considerations, we only present the result for call contracts. 
Figure 3: Average Depth and Trade Size Around the Tick Size Change
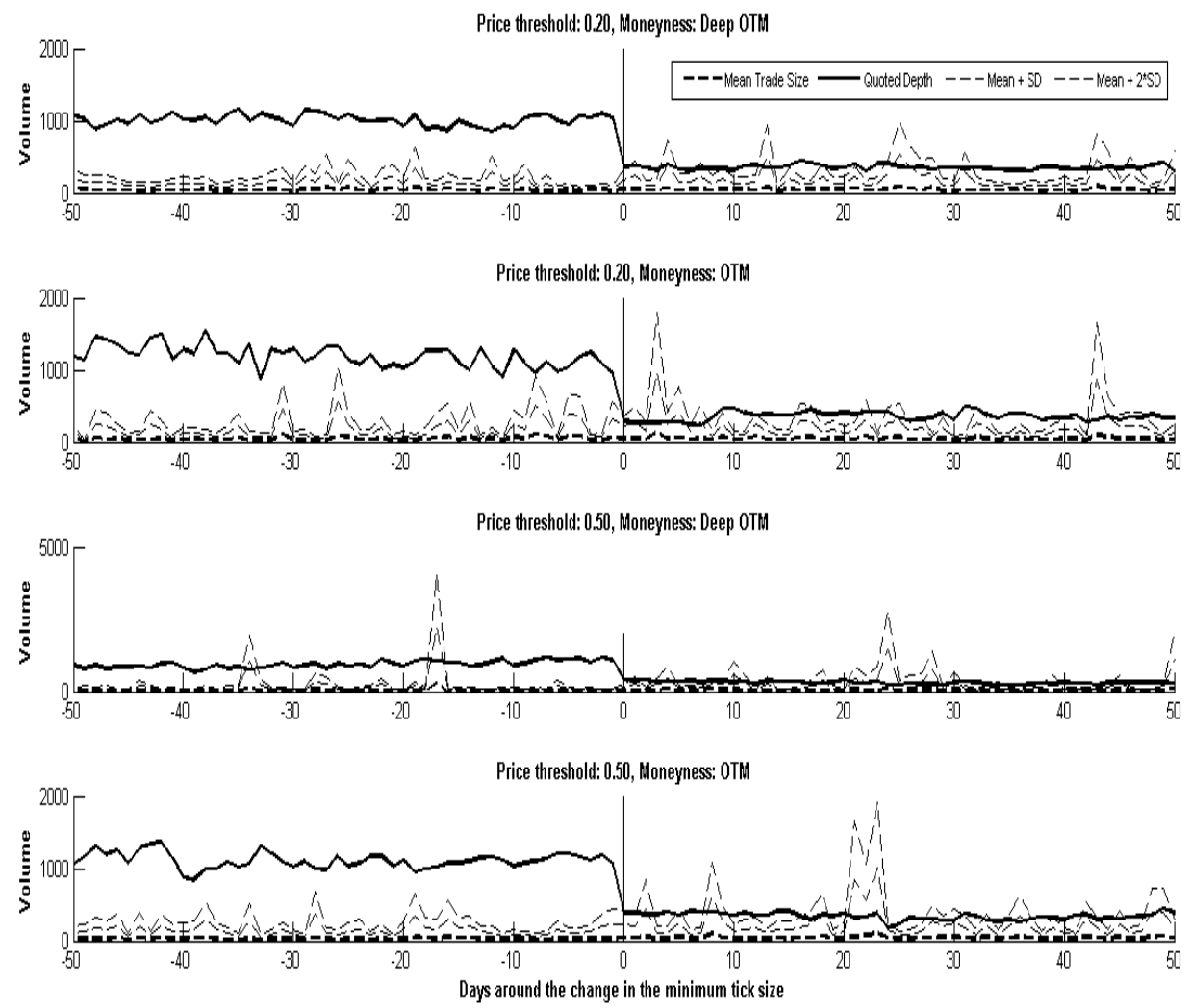

Notes: This Figure plots the average trade size and quote depth the around the implementation of the PBTS. $S D$ refers to the standard deviation of the mean trade size. For the first (last) two plots, the horizontal axis refers to days to and from to June 2, 2009 (April 1, 2010) (day 0). Due to space considerations, we only present the result for call contracts. 
Figure 4: Mean Quote Improvement Around the Tick Size Changes
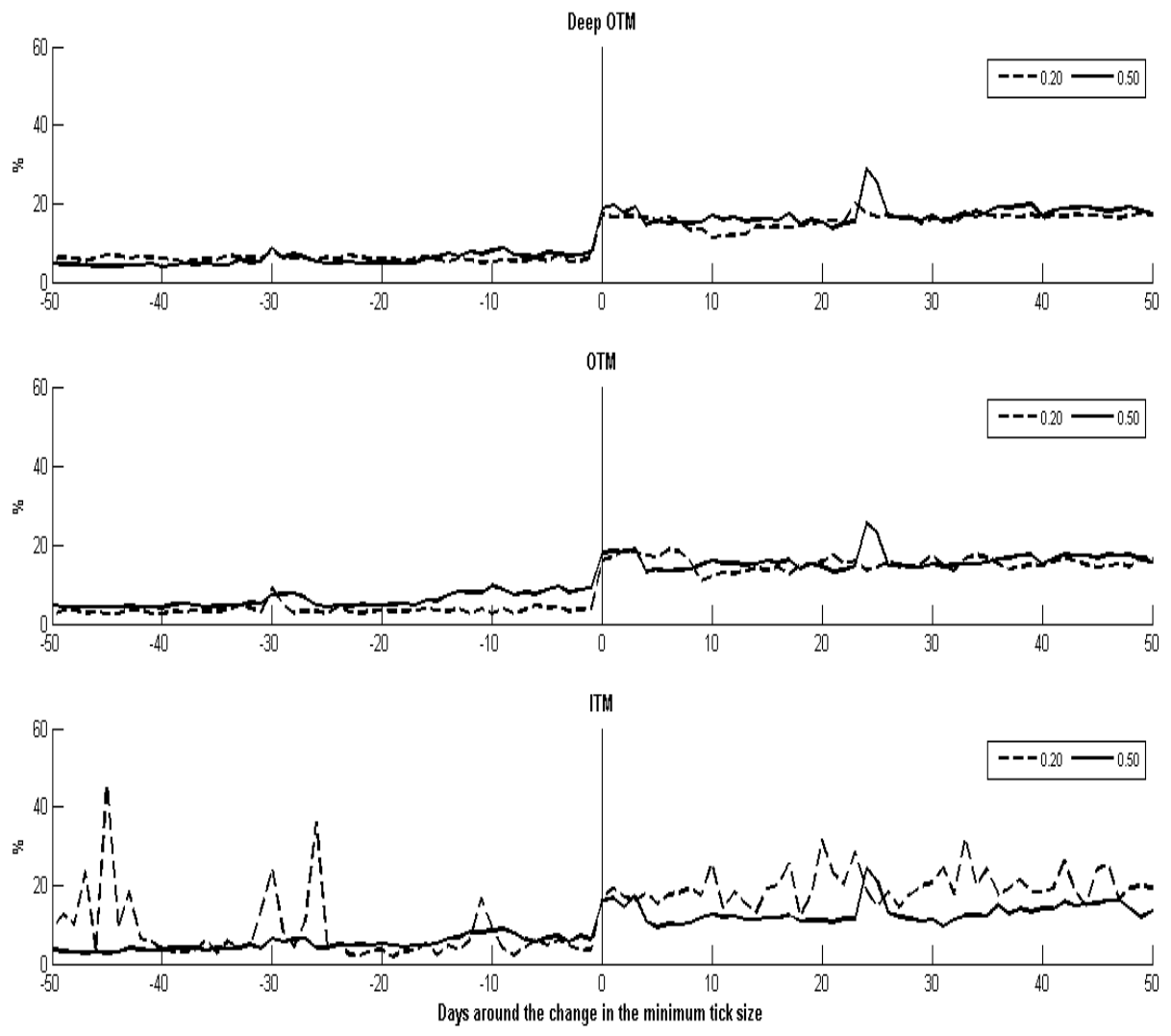

Notes: This figure plots the percentage of price improvement for the periods before and after the implementation of the two stages of PBTS. We classify a new best bid or best ask as a price improvement when the new ask is smaller than the previous ask or the new bid is greater than the old bid. The horizontal axis refers to days to and from the $1^{\text {st }}$ and $2^{\text {nd }}$ stage of PBTS. 